\title{
Analysis of Extreme Water Levels in the Lower Chesapeake Bay
}

Carissa N. Wilkerson

College of William and Mary - Virginia Institute of Marine Science

Follow this and additional works at: https://scholarworks.wm.edu/etd

Part of the Oceanography Commons

\section{Recommended Citation}

Wilkerson, Carissa N., "Analysis of Extreme Water Levels in the Lower Chesapeake Bay" (2013).

Dissertations, Theses, and Masters Projects. Paper 1539617934.

https://dx.doi.org/doi:10.25773/v5-wzxk-2q69

This Thesis is brought to you for free and open access by the Theses, Dissertations, \& Master Projects at W\&M ScholarWorks. It has been accepted for inclusion in Dissertations, Theses, and Masters Projects by an authorized administrator of W\&M ScholarWorks. For more information, please contact scholarworks@wm.edu. 
ANALYSIS OF EXTREME WATER LEVELS IN THE LOWER CHESAPEAKE BAY

\author{
A Thesis \\ Presented to \\ The Faculty of the School of Marine Science \\ The College of William and Mary in Virginia
}

In Partial Fulfillment

Of the Requirements for the Degree of

Master of Science

by

Carissa N. Wilkerson

2013 


\section{Approval Sheet}

This thesis is submitted in partial fulfillment of the

Requirements for the degree of

Master of Science

August, 2013

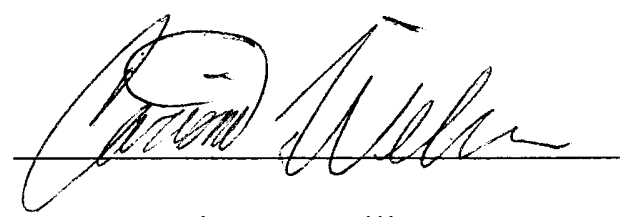

Carissa N. Wilkerson

Academic Committee Members

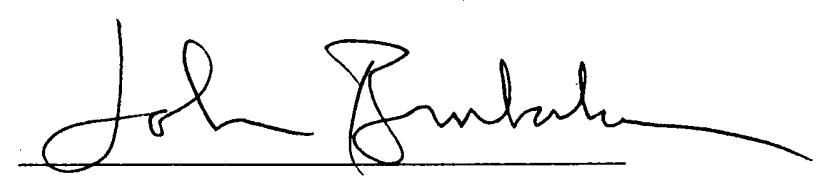

Dr. John Brubaker Advisor

Cal Freduel

Dr. Carl Friedrichs

Co-Advisor

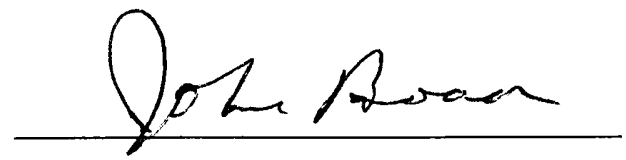

Dr. John Boon

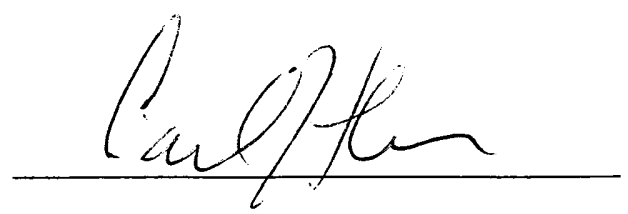

Dr. Carl Hershner 


\section{Dedication}

In loving memory of Dr. George Burbanck, whose happiness and passion for science inspired me. 


\section{Table of Contents}

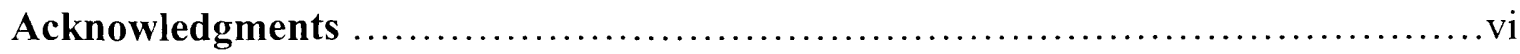

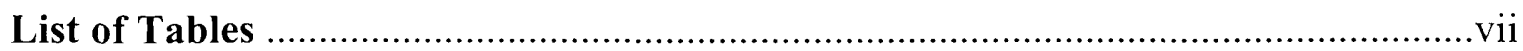

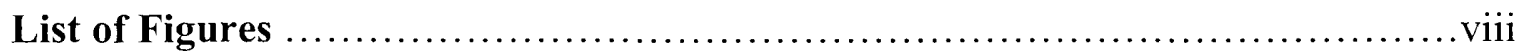

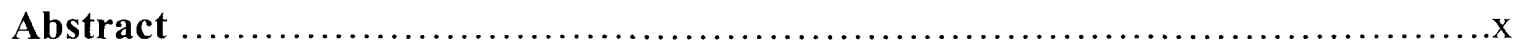

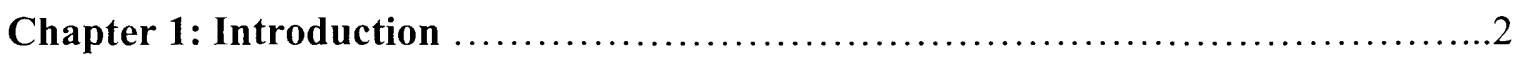

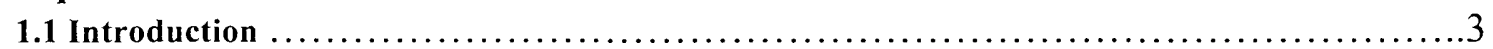

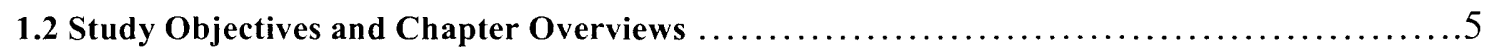

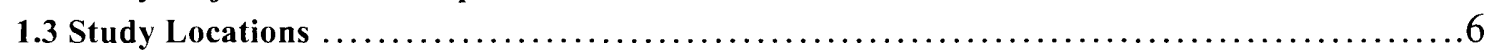

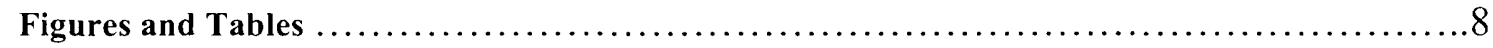

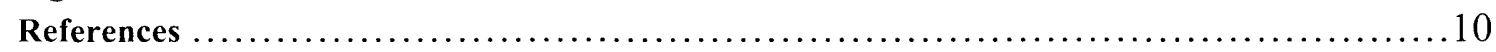

Chapter 2: Contributions to Storm Tide and Their Implications for Future

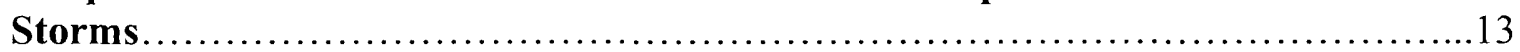

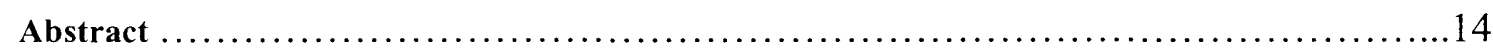

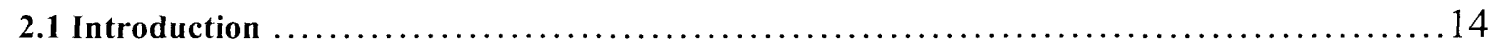

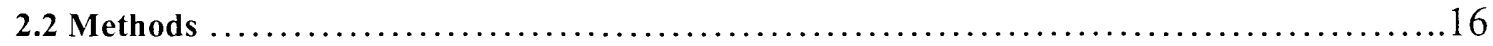

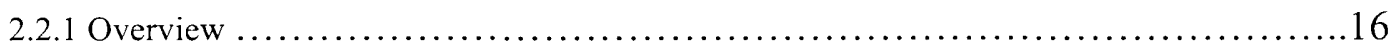

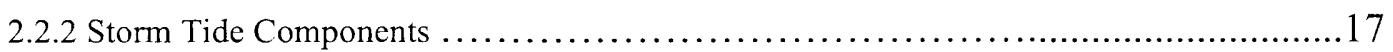

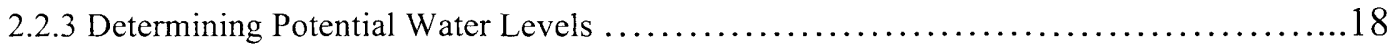

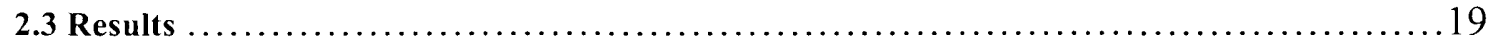

2.3.1 The Presence of Pre-Storm Anomalies ..................................... 19

2.3.2 Comparison of the Two Storm Surges ....................................... 20

2.3.3 Potential Water Levels ................................................ 20

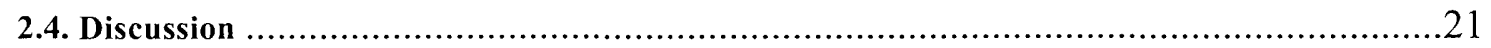

2.4.1 Pre-storm Anomaly Influence on Storm Tide Levels . ..........................21

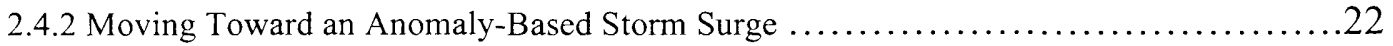

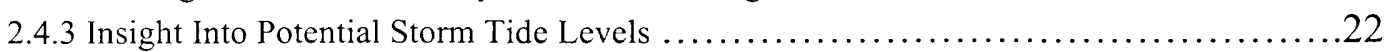

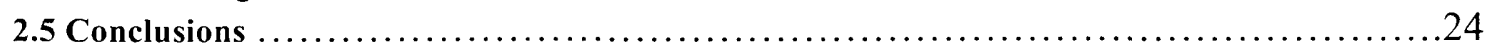

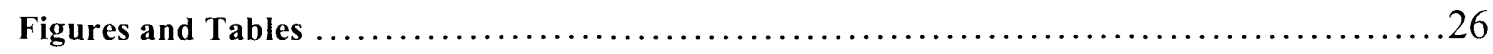

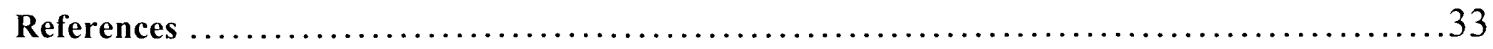

Chapter 3: Spatial and Temporal Variability of Storm Tide Components and the

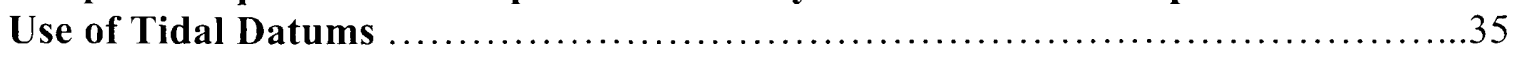

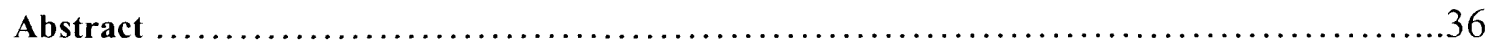

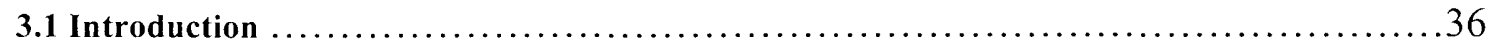

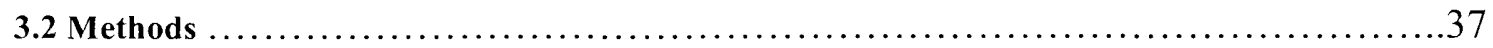

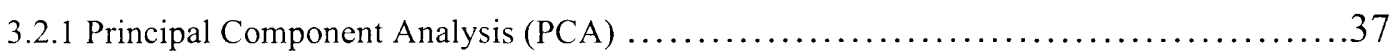

3.2.2 Storm Tides Relative to Highest Astronomical Tide ............................... 39

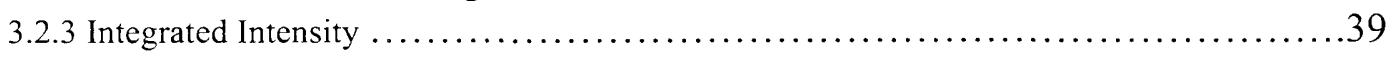

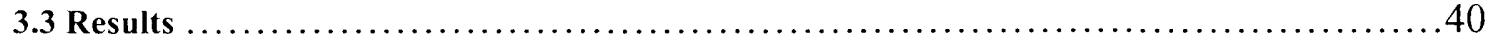


3.3.1 Spatial Variations of Storm Tides and Individual Components

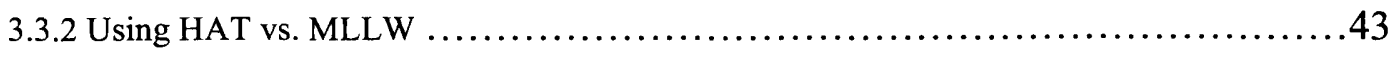

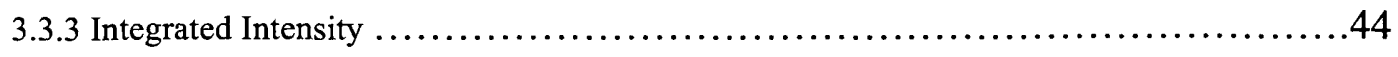

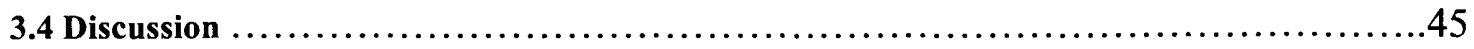

3.4.1 Identifying Spatial Trends in Storm Tide Components ...........................45

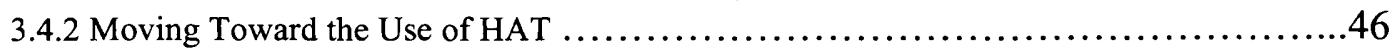

3.4.3 Spatial and Temporal Trends in Integrated Intensity ...........................47

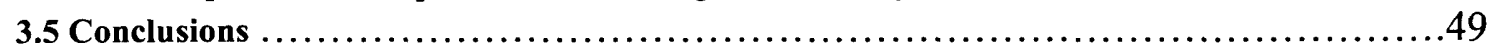

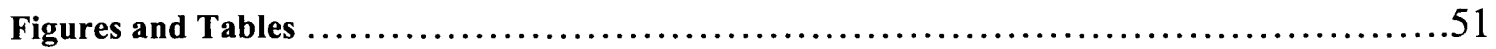

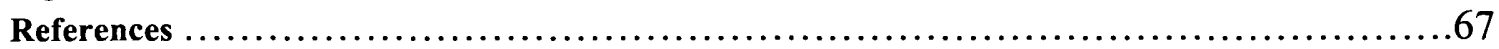

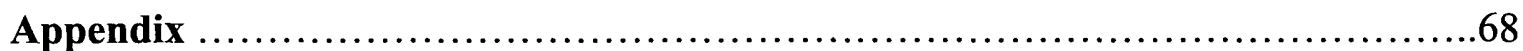

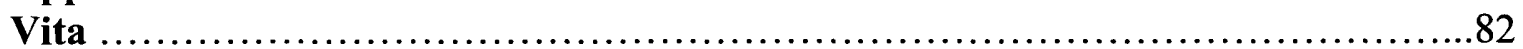




\section{Acknowledgments}

I am extremely grateful for everyone that helped me through my master's degree. First, this research would not have been possible without the support of my major advisors, Drs. John Brubaker and Carl Friedrichs. They allowed me to put my research interests into action and produce research that I am very proud to put my name on. Dr. Brubaker was very patient with me and always gave me additional attention when I struggled with certain concepts. He was the best advisor anyone could ask for! I'm also very thankful to Dr. Friedrichs for filling in the funding gaps and allowing me to gain research experience in the Coastal Hydrodynamics and Sediment Dynamics (CHSD) Laboratory. I am also thankful for my committee members, Dr. John Boon and Carl Hershner. Dr. Boon has been a critical force in my thesis research and exposed me to new concepts in climate science. Dr. Hershner has provided excellent support from a biologist's perspective that also got me interested in coastal management. Although Dr. John Milliman was not on my committee, he brought out my inner geologist and exposed me to a side of oceanography that I plan to pursue for a Ph.D. I am grateful for his advice and expertise.

I received funding from the National Science Foundation GK-12 program during the final year of my master's program. I've gained invaluable teaching experience through this fellowship that I will carry with me for the rest of my career. I would like to thank Drs. Kam Tang, Iris Anderson, and Carol Hopper Brill for providing me with this experience. Dr. Hopper Brill was especially helpful in developing lessons and providing advice.

Finally, I would not have made it through without the unconditional love and support from my partner in life, Keenan Jackson, my mother, Sandra Liss, my father, Dave Wilkerson and two brothers, David Wilkerson and Strafford Foster. They believed in me when I didn't have the confidence to believe in myself and I am grateful to have such a loving family. I'd also like to thank a few very special professors from Hampton University that have greatly influenced my career path. Dr. George P. Burbanck, who passed away in 2012, deeply cared about all of his students and gave me invaluable advice and research experience. Dr. Deidre Gibson not only provided me with research experience, but also the chance to sharpen my informal education skills, something that has helped me greatly in my master's program. Dr. Andrij Horodysky provided excellent career advice and insight into the VIMS community. Dr. Benjamin Cuker has been one of the most influential people in my career. He provided me opportunities to attend scientific conferences as an undergraduate and also provided much of my funding throughout the first two years of my degree through the NSF Hall Bonner Fellowship. Last but certainly not least I would like to thank Dr. Grace Cartwright for always believing in me and providing all the emotional and scientific support, Kelsey Fall for being a wonderful lab mate, friend and math expert, and everyone else who made my experience at VIMS so wonderful! 


\section{List of Tables}

Table

Table 1.1: List of storms used in this study

Table 2.1: Differences between maximum observed water level and 13-year potential high.

Table 3.1: Station rankings of maximum heights relative to MLLW and HAT for Tropical Storm Ernesto.

Table 3.2: Station rankings of maximum heights relative to MLLW and HAT for the Columbus Nor'easter. 


\section{List of Figures}

Figure

Figure 1.1: Map of tide gauge locations

Figure 2.1: A conceptual diagram of the average seasonal cycle and where each of the eleven storms fell during the cycle.

Figure 2.2: Anomaly values for each storm at each station.

Figure 2.3: Anomaly contribution to storm tide in both value and percentage for three stations during (A) Twin Nor'easter 1, (B) Hurricane Floyd, and (C) Nor'Ida.

Figure 2.4: Storm surge values using both the residual-based method and the anomalybased method for (A) Twin Nor'easter 1, (B) Twin Nor'easter 2, (C) Hurricane Floyd, (D) Columbus Nor'easter, and (E) Nor'ida.

Figure 2.5: The potential low and potential high water levels, as well as the maximum observed for (A) Hurricane Floyd, (B) Hurricane Isabel, (C) Thanksgiving Nor'easter, and (D) Hurricane Irene.

Figure 2.6: Maximum observed water level out of all storms and the 13-year potential maximum for all stations

Figure 3.1: Anomaly values for each station during each storm.

Figure 3.2: PCA outcome for the local anomaly.

Figure 3.3: Maximum surge values for each station during each storm.

Figure 3.4: PCA outcome for maximum storm surge.

Figure 3.5: Maximum surge values, excluding Washington, D.C. and Tropical Storm Ernesto.

Figure 3.6: PCA outcome for maximum storm surge, excluding Washington, D.C. and Tropical Storm Ernesto.

Figure 3.7: The great diurnal range, or difference in height between mean higher high and mean lower low water, for nine LCB station.

Figure 3.8: The total number of hours above HAT over the study period for each station. 
Figure

Figure 3.9: Hours above HAT per station per year over the study period.

Figure 3.10: Hours above HAT shown for each station during each storm.

Figure 3.11: The maximum storm tide relative to MLLW for each station and storm.

Figure 3.12: Maximum storm tide relative to HAT for each station and storm.

Figure 3.13: Integrated values for each storm at each station.

Figure 3.14: PCA outcome for the integrated intensity. 


\section{Abstract}

In order to better understand storm tides in the Lower Chesapeake Bay, water levels during eleven storms at eight stations were analyzed using several methods. Storm tide was separated into individual components: predicted tide, storm surge, and local anomaly. These components were quantified and then analyzed for spatial trends. Trends were verified using Principal Component Analysis (PCA). The predicted tide and the storm surge each exhibited spatial variability, while the anomaly was spatially uniform. Anomaly values varied from storm to storm, ranging from $0.01 \mathrm{~m}$ to $0.3 \mathrm{~m}$.

Potential water levels were determined for each storm by applying a time-shift to match the minimum or maximum predicted tide with the maximum storm surge and the anomaly. In many cases if the maximum observed level had occurred at high tide, the potential observed could have been as much as $0.5 \mathrm{~m}$ larger than actually experienced. If the maximum observed level had occurred at low tide, the potential observed level could have been as much as $0.8 \mathrm{~m}$ lower. Thirteen-year potential maximum results indicate that this potential maximum has not been reached at any station. Stations are between $0.3 \mathrm{~m}$ and $0.5 \mathrm{~m}$ away from their thirteen-year potential maximum.

Maximum storm tide values were assessed relative to both mean lower low water (MLLW) and highest astronomical tide (HAT). HAT was determined to be a better metric for storm impact than MLLW. Integrated intensity, or area under the storm tide curve relative to HAT, is a metric that combines storm duration with the height above HAT. Integrated intensity values were generally higher during extratropical storms than during tropical storms due to the long duration of these storms. 
Analysis of Extreme Water Levels in the Lower Chesapeake Bay 


\section{Chapter 1}

\section{Introduction}




\subsection{Introduction}

The lower Chesapeake Bay (LCB) experiences coastal flooding due to both tropical and extratropical systems. In the mid-latitudes of the North Atlantic Ocean, hurricanes are most common from June through September while nor'easters generally occur from October to May (Zhang et al., 2000). Hurricanes originate as easterly waves that travel westward over the tropical ocean (Boon, 2004). Hurricanes are more intense than nor'easters, but the intensity is concentrated around the eye of the storm (Boon, 2004, Boon, 2012). Nor'easters usually originate as low-pressure frontal waves between two air masses over the North American Continent, and generally move in the Northeast direction (Boon, 2004). While less intense than hurricanes, nor'easters often cover a larger spatial area and longer time frame (Kim et al., 1998).

Many LCB cities and towns are located in low-lying areas that are prone to inundation during storms. This flooding is often referred to as storm surge; however, a more appropriate term is storm tide. Storm tide is defined as the sum of storm surge, astronomical tide and the local sea level anomaly (Boon, 2012). For any given month in the Chesapeake Bay, the astronomical tide may account for less than 70 percent of the total water level variance (Boon, 2012). The concept of storm tide allows us to account for water level variations unrelated to the storm itself. The storm surge component is the change in water level that would occur in the absence of astronomical tide during a storm in a given coastal area (Boon, 2004), and it may be affected by wind speed and direction, inverse barometer effect and precipitation, as well as other physical factors.

Wind stress and inverse barometric effect together may cause a storm surge (De Lange \& Gibb, 2000, Kleinosky et al., 2007). Inverse barometer occurs when the low- 
pressure center of the hurricane lifts the water beneath it, creating a dome of water that the winds can then push onshore (Kleinosky et al., 2007). The inverse barometer, under ideal, theoretical circumstances, produces about a centimeter of sea level rise per one $\mathrm{hPa}$ decrease in atmospheric pressure (Goring, 1995, De Lange \& Gibbs, 2000, Flather, 2009, Sweet et al., 2009). Since conditions are rarely ideal, deviations from these values may occur.

The local sea level anomaly, if significant, may lead to incorrect assessments of storm severity. Possible mechanisms that can produce an anomaly include winds offshore in the North Atlantic that blow from the northeast causing Ekman transport toward the coast, or changes in the speed of the Florida Current causing sea levels along the U.S. east coast to rise or fall due to a change in slope across the geostrophic current (Sweet et al., 2009). Several studies have addressed questions of sea level variability and storminess. Zhang et al. (2000) created a set of indices to quantify long-term trends of storm activity on the U.S. east coast and used storm surge as a measure. However, they did not account for intraseasonal anomalies that may have contributed to the storm surges. Sweet \& Zervas (2011) investigated short-term variability in storm surge and long-term variability of mean sea level (MSL) over the cool season, relating their results to El Niño. They account for longer-term seasonal anomalies, but not intraseasonal anomalies that may occur on a scale of a few weeks. Additionally, they do not factor in other climatic phenomenon, such as the North Atlantic Oscillation, in interannual sea level variability. Kolker \& Hameed (2007) related changes in the position of the Azores high-pressure system to sea level changes at several North Atlantic stations, including two stations along the U.S. east coast. De Lange \& Gibbs (2000) studied temporal 
variability of storm surges in New Zealand by accounting for storm surges exceeding an arbitrary threshold. They treated each peak above this threshold as a separate storm surge event. Like the other studies mentioned above, De Lange \& Gibb (2000) did not consider the possibility of intraseasonal anomalies.

All of the studies listed above considered large regions (the U.S. east coast, North Atlantic basin). While it is important to establish large-scale trends, there is often a great deal of local variability that communities may be concerned about. Williams et al. (2009) established that in the Atlantic coast of the U.S., Relative Sea Level Rise (RSLR) rates are highest in the mid-Atlantic region, from Northern New Jersey to Southern Virginia. Sallenger et al. (2012) and Boon (2012b) have found that sea level rise is accelerating in the North Atlantic, while Ezer and Corlett (2012) have found that sea level rise is accelerating within the Chesapeake Bay area. The Chesapeake Bay region experiences land subsidence that plays a large role in RSLR. Boon et al. (2010) calculated RSLR and subsidence rates at several stations throughout the Chesapeake Bay, and found that spatial variability in RSLR rates exists. As RSL continues to rise in this region, the threat of inundation to local communities will become greater. However, spatial variability in RSLR and subsidence rates exists throughout the Chesapeake Bay, which may have important implications for future storm tides. For these reasons, it is essential that we observe storm tides and sea levels on a local scale.

\subsection{Study Objectives and Chapter Overviews}

The goals of this study are to 1) quantify the contribution of the three components to overall storm tide level and 2) characterize spatial trends of storm tides so that we can better understand areas that are subject to flooding under certain conditions. Chapter 2 
explores how the three component processes, local anomaly, storm surge and predicted tide, contributed to overall storm tide levels during eleven major storms at eight stations throughout the LCB. A running average of pre-storm water levels was used to determine the pre-storm anomaly. Then, anomaly and predicted tide were subtracted from total observed water level to get storm surge. Additionally, potential water level scenarios were computed for each station using conditions from all eleven storms.

Chapter 3 examines spatial trends of storm tides in three ways: 1) by analyzing spatial trends in each of the storm tide components using Principal Component Analysis (PCA), 2) using the tidal datum Highest Astronomical Tide (HAT) as a flooding impact parameter at each station, and 3) using PCA to sort out spatial variations of integrated intensity, or area under the storm tide curve, which examines height and duration spent above HAT.

\subsection{Study Locations}

The National Oceanic and Atmospheric Administration (NOAA) maintains fifteen active tide gauges in the Chesapeake Bay, eight of which are located in the LCB. These data are available at http://idesandcurrents.noaa.gov. The length of the tidal records differed substantially between the active NOAA stations, ranging from thirteen to eightyfour years. Hourly predicted and verified water level data relative to Mean Sea Level were retrieved. A total of eleven storms, six tropical and 5 extratropical, were selected for analysis (Table 1.1).

For the area of Gloucester Point/Yorktown, the Gloucester Point station data is used from 1996 to 2003 and the York River Coast Guard tide gauge is used from 2004 to 2011. This is due to the destruction of the Gloucester Point tide gauge in 2003 as a result 
of Hurricane Isabel. The York River Coast Guard tide station was installed in 2004 to replace the Gloucester Point station. Since the two stations are within two and a half miles of one another, they are used interchangeably. 
Figures and Tables

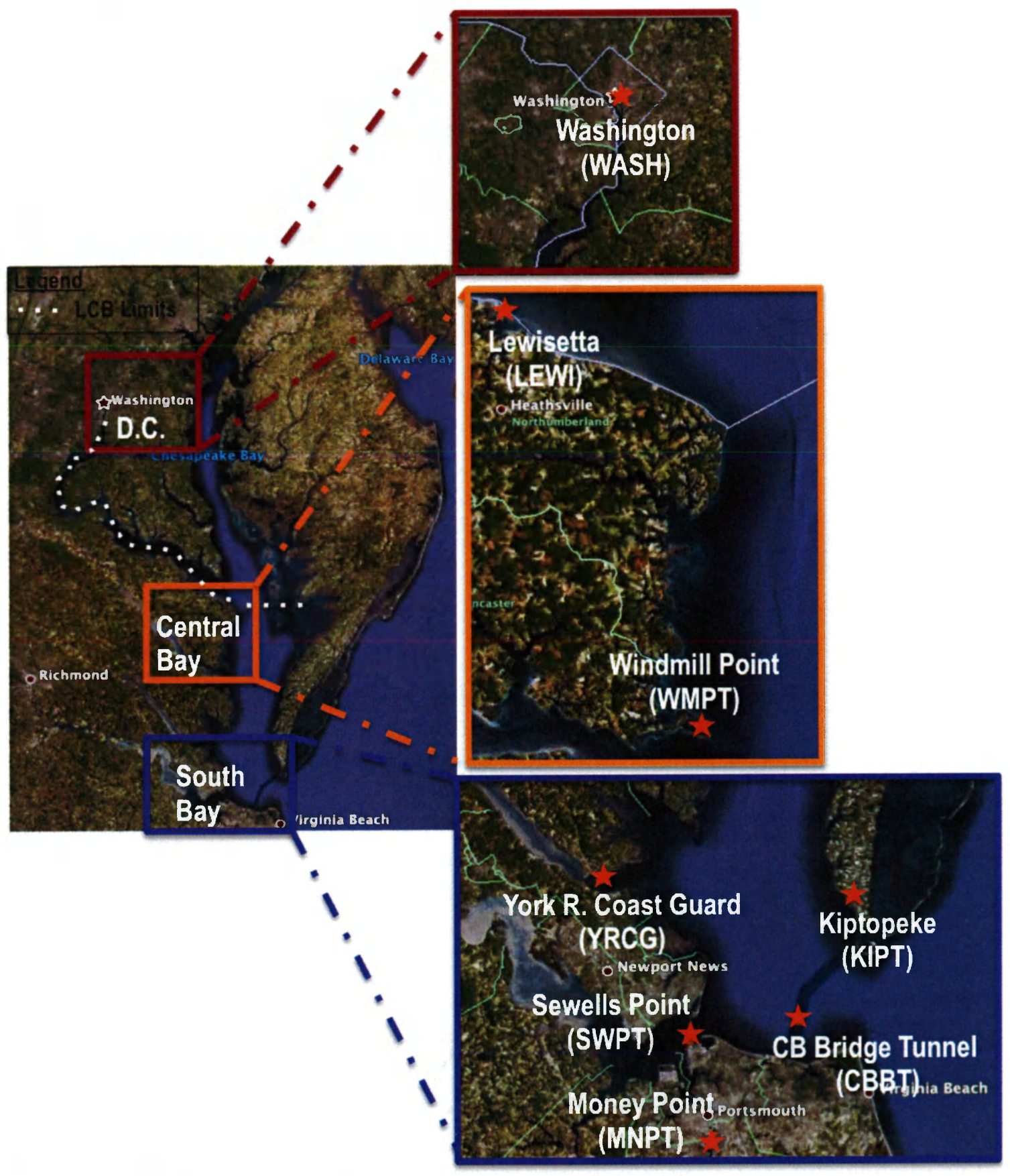

Figure 1.1:NOAA tide gauge locations 
Table 1.1: List of storms selected for this study

\begin{tabular}{|c|c|c|}
\hline Storm Name & Year & Type \\
\hline Hurricane Irene & 2011 & Tropical \\
\hline Nor'Ida & 2009 & Extratropical \\
\hline Thanksgiving Nor'easter & 2006 & Extratropical \\
\hline Columbus Nor'easter & 2006 & Extratropical \\
\hline Tropical Storm Ernesto & 2006 & Tropical \\
\hline Hurricane Isabel & 2003 & Tropical \\
\hline Hurricane Floyd & 1999 & Tropical \\
\hline Hurricane Dennis & 1999 & Tropical \\
\hline Hurricane Bonnie & 1998 & Tropical \\
\hline Twin Nor'easter 2 & 1998 & Extratropical \\
\hline Twin Nor'easter 1 & 1998 & Extratropical \\
\hline
\end{tabular}




\section{References}

Boon, J. D. (2004). Secrets of the tide: Tide and tidal current analysis and applications, storm surges and sea level trends. (p. 134). Cambridge, UK: Woodhead Publishing Limited.

Boon, J., Brubaker, J., Forrest, D. (2010). Chesapeake Bay land subsidence and sea level change: an evaluation of past and present trends and future outlook. Special Report in Applied Marine Science and Ocean Engineering, vol. 425.

Boon, J.D. Sea Level rise and the Impact of Lesser Storms. Workshop on Sea Level Rise and Coastal Infrastructure: Predictions, Risks and Solutions sponsored by the University of Maryland and the American Society of Civil Engineers, Reston VA, June 9-10, 2012 (a). Invited paper submitted for publication in ASCE Monograph (B.M. Ayyub, M. Kearney eds).

Boon, J.D. (2012)(b). Evidence of sea level acceleration at U.S. and Canadian tide stations, Atlantic Coast, North America. Journal of Coastal Research, 28(6), 14371445.

De Lange, W. P., \& Gibb, J. G. (2000). Seasonal, interannual, and decadal variability of storm surges at Tauranga, New Zealand. New Zealand Journal of Marine and Freshwater Research, 34, 419-434. 
Ezer, T., \& Corlett, W.B. (2012). Is sea level rise accelerating in the Chesapeake Bay? A demonstration of a novel new approach for analyzing sea level data. Geophysical Research letters, 39, 1-6.

Flather, R. A. (2009). Storm surges. In J. H. Steele, S. A. Thorpe \& K. K. Turekian (Eds.), Elements of Physical Oceanography (p. 77). London, UK, Burlington, MA, San Diego, CA: Academic Press.

Goring, D. G. (1995). Short-term variations in sea level (2-15 days) in the New Zealand region. New Zealand Journal of Marine and Freshwater Research, 29, 69-82.

Kim, S. C., Chen, J., Park, K., \& Choi, J. K. (1998). Coastal surges from extratropical storms on the west coast of the Korean peninsula. Journal of Coastal Research, 14(2), $660-666$.

Kleinosky, L. R., Yarnal, B., \& Fisher, A. (2007). Vulnerability of Hampton Roads, Virginia to storm-surge flooding and sea-level rise. Natural Hazards, 40, 43-70.

Kolker, A. S., \& Hameed, S. (2007). Meteorologically driven trends in sea level rise. Geophysical Research Letters, 34(23), 1-7. doi: 10.1029/2007GL031814 
Sallenger, A. H., Doran, K. S., \& Howd, P. A. (2012). Hotspot of accelerated sea-level rise on the Atlantic coast of North America. Nature Climate Change, 2(7), doi: $10.1038 /$ nclimate 1597

Sweet, W., Zervas, C., \& Gill, S. U.S. Department of Commerce, National Oceanic and Atmospheric Administration, National Ocean Service. (2009). Elevated east coast sea levels anomaly, june-july, 2009 (NOAA Technical Report NOS CO-OPS 051). Silver Spring, Maryland: Center for Operational Oceanographic Products and Services.

Sweet, W. V., \& Zervas, C. (2011). Cool season sea level anomalies and storm surges along the U.S. east coast: Climatology and comparison with the 2009-2010 El Niño. Monthly Weather Review, 139(7), 2290-2299.

Williams, S. J., Gutierrez, B. T., Titus, J. G., Gill, S. K., Cahoon, D. R., Thieler, E. R., Anderson, K. E., FitzGerald, D., Burkett, V., Samenow, J. (2009). Sea level rise and its effects on the coast. In: Coastal Sensitivity to Sea-Level Rise: A Focus on the MidAtlantic Region. A report by the U. S. Climate Change Science Program and the Subcommittee on Global Change Research. U. S. Environmental Protection Agency, Washington DC, pp. 11-24

Zhang, K., Bruce, C. D., \& Leatherman, S. P. (2000). Twentieth century storm activity along the U.S. East Coast. Journal of Climate, 13(10), 1748-1761. 


\section{Chapter 2}

Contributions to Storm Tide and Their Implications for Future Storms 


\section{Abstract}

Three components of storm tide were quantified for eleven storms at eight stations in the Lower Chesapeake Bay. Pre-storm anomalies were found by applying a running average to pre-storm water levels. Water level anomalies prior to the storms in this study ranged from $0.01 \mathrm{~m}$ to $0.3 \mathrm{~m}$. The anomaly and the predicted tide were subtracted from the observed water levels to give the anomaly-based storm surge. Since all of the anomalies were positive, surge values by this approach were smaller than would have been estimated without accounting for pre-storm anomaly. Potential water levels were also determined for each storm by applying a time-shift to match the minimum or maximum predicted tide with the maximum storm surge and the anomaly. The outcome was a potential minimum and potential maximum value. Two storms in particular had maximum observed levels at some stations equal to or close to the potential maximum, indicating that the maximum storm surge occurred near high tide. During Hurricanes Floyd and Irene, some stations experienced their maximum storm surge at low tide. A thirteen-year potential maximum was calculated for each station and compared to the highest level observed at each station during the study period. Results show that no station has reached its potential maximum in terms of our analysis.

\subsection{Introduction}

The Lower Chesapeake Bay (LCB) is frequently visited by hurricanes and nor'easters that can produce damaging storm tides. Storm tide has previously been defined as the sum of the predicted tide and storm surge. However, recent research by Boon (2010) showed that an additional term, the local sea level anomaly, should also be considered when calculating overall storm tide. Each component of storm tide may be 
influenced by different physical forcing. The local anomaly may be a result of several processes, such as winds located far offshore producing Ekman transport onshore, changes in the slope of geostrophic currents due to changes in speed (Sweet et al., 2009), and local meteorological forcing, such as persistent winds over a given timespan. Storm surge is heavily influenced by storm track, wind speed and direction, and sometimes wave setup, precipitation/runoff and the inverse barometer effect (Goring, 1995, De Lange \& Gibbs, 2000, Flather, 2009, Sweet et al., 2009). Storm surge can also be influenced by Ekman transport produced from the winds of a storm. The tidal component of storm tide is predicted by the National Oceanic and Atmospheric Administration, and is a result of gravitational pull of the moon, and to a lesser degree, the sun. Several tidal constituents are considered in the calculation of the predicted tide, but the five most prominent constituents that describe over three-quarters of the daily variation include the main lunar semidiurnal $\left(\mathrm{M}_{2}\right)$, the main solar semidiurnal $\left(\mathrm{S}_{2}\right)$, the larger lunar elliptical semidiurnal $\left(\mathrm{N}_{2}\right)$, lunar-solar declination diurnal $\left(\mathrm{K}_{1}\right)$ and the lunar declination diurnal $\left(\mathrm{O}_{1}\right)$ (Boon, 2004). Two additional constituents, the Solar Annual (Sa) and Solar Semiannual (Ssa), theoretically account for the nonuniform changes in the Sun's declination and distance. In actuality, these two constituents represent the average seasonal cycle of the tides due to meteorological forcing (Sweet et al., 2009). The Chesapeake Bay experiences semidiurnal tides, or two high and two low tides per day.

Previous research by Kleinosky et al. (2007) suggested that many areas of Hampton Roads, Virginia are susceptible to flooding during hurricanes. Five of the eight stations used in this study are located in Hampton Roads. They quantified the potential area of land in each city that would be influenced by storm surge under different 
hurricane category scenarios. One of the worst areas for flooding during even weak storms was the Elizabeth River, where one of the tide gauges in this study (Money Point) is located.

All of the studies mentioned above have provided insight into storm surges and storm tides in the LCB. However, further work is needed to quantify the contribution of the three component processes to overall storm tide. Additionally, more research is required into potential water levels during future storms. This study aims to fill in some of the gaps between previous research on storm tides and what is still unknown.

There are two main goals of this study: 1) to quantify the relative contribution of the component processes that collectively produced storm tides in the LCB, and 2) to explore potential water level of past and future storms. The following questions will be addressed in this chapter:

1. To what extent has the local anomaly contributed to storm tide?

2. What role does tidal cycle timing play in storm tide levels?

\subsection{Methods}

\subsubsection{Overview}

NOAA and others have defined storm tide as the sum of the predicted tide, $h_{p}$, and the storm surge, $\mathrm{h}_{\mathrm{s}}$. In this study, storm tide contains an additional component, the local water level anomaly, $h_{a}$ :

$$
\mathrm{h}_{\mathrm{o}}=\mathrm{h}_{\mathrm{s}}+\mathrm{h}_{\mathrm{p}}+\mathrm{h}_{\mathrm{a}} \text { (Eq. 2.1) }
$$

where $h_{o}$ is total observed water level. In this generic expression of the concept, the various terms could be determined, in principle, in different possible ways. For example, the predicted tide could be computed by harmonic analysis of selected data, storm surge 
could be estimated by a numerical hydrodynamic model, etc. In this study, however, a combination of observed water level data and NOAA predicted tides will be used to determine storm surge as a residual. Note that all data analyzed in this chapter are relative to mean sea level (MSL).

\subsubsection{Storm Tide Components}

Though calculating the storm surge using equation 2.1 seems straightforward, the predicted tide and the local pre-storm anomaly must be specified in more detail. NOAA predicted tides, $\mathrm{h}_{\mathrm{pN}}$, include the desired astronomical forcing, but as noted above, also include an average seasonal cycle, reflecting mostly meteorological forcing, in the Sa and Ssa constituents. To separate out the astronomical forcing, a 30-day running average of NOAA predicted tides $\left(<\mathrm{h}_{\mathrm{pN}}>_{30}\right)$ was applied, which produced the average seasonal cycle (Figure 2.1). Then, the average seasonal cycle was subtracted from the original NOAA predicted tide to get an adjusted predicted tide $\left(\mathrm{h}_{\text {padj }}\right)$ that does not include the seasonal signal:

$$
\mathrm{h}_{\mathrm{padj}}=\mathrm{h}_{\mathrm{pN}}-<\mathrm{h}_{\mathrm{pN}}>_{30} \text { (Eq. 2.2) }
$$

It is important to account for the average seasonality built into the tidal predictions because actual conditions when a storm arrives, as represented by the prestorm anomaly term to be considered next, will differ from the average, causing the overall storm tide to be higher or lower. Figure 2.1 shows the timing of the storms of this study relative to the average seasonal cycle. It is equally important to accurately attribute observed water levels to the correct component. 
The final component to quantify before calculating storm surge is the local prestorm anomaly. This was determined using a thirty-day running average of observed water levels prior to the beginning of the storm:

$$
\mathrm{h}_{\mathrm{aobs}}=<\mathrm{h}_{\mathrm{o}}>_{30}(\text { Eq. 2.3) }
$$

The last value produced from the running average on the day prior to the storms' beginning date was selected as the anomaly

Now that the predicted tide and local pre-storm anomaly have been defined, a specific computation of storm surge can be introduced as follows: in equation (2.1) substitute $h_{p}=h_{\text {padj }}$ from Eq 2.2 and $h_{a}=h_{\text {aobs }}$ from Eq. 2.3. Solving for storm surge:

$$
h_{s}=h_{o}-h_{\text {padj }}-h_{\text {aobs }} \text { (Eq. 2.4) }
$$

For comparison, some values of surge that would be obtained without accounting for prestorm anomaly are presented below as a reference surge:

$$
\mathrm{h}_{\text {sref }}=\mathrm{h}_{\mathrm{o}}-\mathrm{h}_{\text {padj }} \text { (Eq. 2.5) }
$$

The pre-storm anomaly-based surge described by Eq. 2.4 will simply be referred to as the anomaly-based surge throughout the rest of this paper.

\subsubsection{Determining Potential Water Levels}

Two cases for potential water levels were created for each storm at each station using actual storm and water level conditions. The first case gives the potential maximum water level $\left(\mathrm{P}_{\max }\right)$ using the original anomaly, but aligning the maximum storm surge $\left(\mathrm{h}_{\mathrm{s}(\max )}\right)$ with the maximum adjusted predicted tide $\left(\mathrm{h}_{\mathrm{padj}(\max )}\right)$ from the storm period (Eq. 2.6). This shows what water levels could have been if the maximum storm surge occurred at high tide. The second case gives the potential minimum water $\left(\mathrm{P}_{\min }\right)$. A similar method 
to Eq. 2.6 was used to calculate the potential minimum water level, except the minimum adjusted predicted tide ( $\left.\mathrm{h}_{\text {padj(min) }}\right)$ was used rather than the maximum (Eq. 2.7)

$$
\begin{aligned}
& P_{\max }=h_{s(\max )}+h_{\text {padj(max })}+h_{a} \text { (Eq. 2.6) } \\
& P_{\min }=h_{s(\max )}+h_{\text {padj(min) }}+h_{a}(E q 2.7)
\end{aligned}
$$

In order to determine what the maximum water levels at each station could be if maxima of the three storm tide components from past storms coincided, a thirteen-year potential maximum was calculated for each station using conditions from all eleven storms.

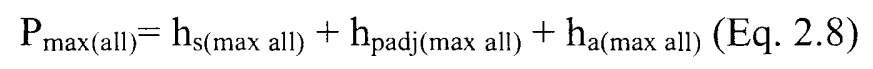

First, the highest surge was calculated for each storm at each station. From there, the thirteen-year potential maximum surge was found by selecting the largest of the highest surge values from all the storms at each station. The same process was repeated to find the maximum predicted tide and the maximum anomaly.

\subsection{Results}

\subsubsection{The Presence of Pre-Storm Anomalies}

Pre-storm water level anomalies ranged from $0.01 \mathrm{~m}$ to $\sim 0.3 \mathrm{~m}$ and accounted for $<1 \%$ up to $32 \%$ of the total observed water level above MSL. Principal Component Analysis (PCA) was used to test spatial variability of the local pre-storm anomaly. The spatial aspect of anomaly will be further quantified and discussed in chapter 3 , but as a preview, results indicated that the anomaly was spatially fairly uniform across the stations of this study. Thus, only one representative station is shown for each section of the LCB. Though spatial variability was limited, anomaly values did vary by storm (Figure 2.2). Anomaly values were negligible for Twin Nor'easter 1, and thus accounted 
for almost none of the total observed water level (Figure 2.3a). The most substantial anomalies occurred prior to Nor'Ida in 2009 (Figure 2.3c), with values ranging from $0.23 \mathrm{~m}$ to $\sim 0.3 \mathrm{~m}$ throughout the LCB. However, anomaly accounted for the highest percentage of total water level during Hurricane Floyd in 1999, ranging from $15.5 \%$ at Kiptopeake to $32 \%$ at Washington, D.C (Figure $2.3 \mathrm{~b}$ ).

\subsubsection{Comparison of the Two Storm Surges}

Storm surge varied spatially throughout the LCB, whether the reference surge or the anomaly-based surge was used (Figure 2.4, a-e). Differences between the reference and the anomaly-based surges varied substantially between storms, and to a lesser degree between stations. The two were essentially equal during Twin Nor'easter 1 (Figure 2.4a), while the difference was up to $0.25 \mathrm{~m}$ during Hurricane Floyd (Figure 2.4c) and nearly $0.3 \mathrm{~m}$ during Nor'Ida (Figure $2.4 \mathrm{e}$ ). Minor spatial variability was observed between the two surges for most storms ranging from a $0.04 \mathrm{~m}$ difference during the Columbus Nor'easter (Figure 2.4d) to a $0.09 \mathrm{~m}$ difference during Twin Nor'easter 2 (Figure 2.4b), which is consistent with the general spatial uniformity discussed in chapter 3 .

\subsubsection{Potential Water Levels}

During each storm, except for Nor'Ida, at least one station had observed water levels within $0.1 \mathrm{~m}$ of the potential maximum (Figure 2.5). Four storms in particular had multiple stations with observed water levels at or near the potential high. These storms were Hurricane Floyd, Hurricane Isabel, Thanksgiving Nor'easter and Hurricane Irene (Figures 2.6 a-d). During Hurricane Floyd, all South Bay stations except for Gloucester Point were within $0.1 \mathrm{~m}$ of their potential high. All stations that had available data during Hurricane Isabel had maximum observed water levels near the potential high, indicating 
that the maximum surge occurred at high tide. For Hurricane Irene, the maximum surge also occurred at high tide at all South Bay stations except for York River Coast Guard. In many cases if the maximum storm surge had occurred at high tide, the potential observed could have been as much as $0.5 \mathrm{~m}$ larger than actually experienced. If the maximum storm surge had occurred at low tide, the potential observed level could have been as much as $0.8 \mathrm{~m}$ lower.

Thirteen-year potential maximum results shows that no station has reached its potential height. The maximum observed water levels at Chesapeake Bay Bridge Tunnel, Sewells Point, Money Point and Gloucester Point are all over $0.5 \mathrm{~m}$ away from their thirteen-year potential maximum. Kiptopeake, Windmill Point and Lewisetta are over $0.3 \mathrm{~m}$ from their potential maximums (Table 2.1). Washington, D.C. could not be included due to missing data prior to the storm with the highest observed level, Hurricane Isabel.

\subsection{Discussion}

\subsubsection{Pre-storm Anomaly Influence on Storm Tide Levels}

Pre-storm water level anomalies made a large contribution to storm tide levels

during Twin Nor'easter 2, Hurricane Floyd, Columbus Nor'easter and Nor'Ida. The large pre-storm anomaly value for Hurricane Floyd can partially be described by the influence of Hurricane Dennis. Since the two storms occurred within two weeks of one another and the anomaly is calculated using a thirty-day running average of pre-storm levels, high water levels from Hurricane Dennis were inevitably considered in the calculation of anomaly. The same is true for Twin Nor'easter 2 because Twin Nor'easter 1 occurred one-week prior. Perhaps using a shorter averaging length would tease out some of these 
issues. However, a shorter averaging length may capture only part of a cycle for certain tidal constituents. Nor'Ida did not have another storm occur prior to it, yet water levels were running high for several weeks prior to the storm.

Though most people are not concerned with what contributes to overall storm tide levels, an important outcome of this analysis is that more attention should be paid to abnormal water levels prior to any given storm. If water levels are running high prior to a storm, then they will likely contribute to storm tide levels as well, as seen during Hurricane Floyd and Nor'Ida. Additionally, if water levels are running low prior to a storm, it could lessen the impact on coastal communities. Incorporating anomalies into storm surge calculations will allow for a better forecast of storm surge throughout the LCB.

\subsubsection{Moving Toward an Anomaly-Based Storm Surge}

Storm surge was calculated using a new, anomaly-based approach. For storms such as Twin Nor'easter 2, Hurricane Floyd, Columbus Nor'easter and Nor'Ida, the storm surge calculated using the anomaly-based method was lower than the surge calculated using the reference method. This is because the reference method does not account for anomaly; therefore, part of what is considered surge is actually anomaly. For Twin Nor'easter 1 the difference between the reference and anomaly-based surges was negligible. Though results varied between storms, using the anomaly-based surge identified and accounted for water levels unrelated to the tide and the storm itself.

\subsubsection{Insight Into Potential Storm Tide Levels}

Using actual storm conditions, a time shift was applied to water level data in order to line up the maximum surge for each station with the minimum predicted tide. This was 
also applied to the maximum predicted tide. By shifting the time of the predicted tide, the potential low and high water level of each storm was found. This provided insight into how much better or worse the storm impact could have been if the maximum storm surge occurred at low or high tide, respectively. The maximum observed water level for all stations during Hurricane Isabel and all South Bay stations except for York River Coast Guard during Hurricane Irene was at or very close to the potential high for those storms. This suggests that the maximum storm surge occurred near high tide for these storms and stations. During Hurricane Irene at Lewisetta, the maximum observed level was essentially at potential low, suggesting that the maximum storm surge occurred at low tide.

Hurricane Floyd was a special case where the maximum observed level at most South Bay stations was within $0.1 \mathrm{~m}$ of the potential high, while the maximum observed level at the Central Bay stations was essentially at the potential low. This pattern indicates that the arrival time of the storm relative to tidal phasing played a vital role in spatial variability.

Kleinosky et al. (2007) found that much of Hampton Roads, Virginia, where five of the study locations used in this analysis are located, is vulnerable to storm surge flooding. In particular, they found that communities along the Elizabeth River are susceptible to flooding from weak hurricanes. One of the stations used in this study, Money Point, is located on the Elizabeth River. This station displayed a trend of higher storm surges than the rest of the stations, which is in agreement with the findings of Kleinosky et al. (2010). Additionally, they found that the town of Poquoson is extremely susceptible to flooding. The Virginia Institute of Marine Science has set up a tide gauge 
in Back River, Virginia that captures water level fluctuations relevant to the city of Poquoson. Analysis of the data from the Back River tide gauge may provide more insight into the findings of the Kleinosky study.

\subsection{Conclusions}

There is an increasing concern of flooding impact in the Lower Chesapeake Bay due to hurricanes and nor'easters, which frequently visit the area. Results presented in this study show that flooding could be worse if water levels are elevated prior to a storm. Two distinct storms within the past thirteen years, Hurricane Floyd and Nor'Ida, have exhibited particularly large pre-storm water level anomalies, accounting for up to $0.3 \mathrm{~m}$ of total storm tide and up to $32 \%$ of the total observed water level relative to MSL. Two additional storms, Twin Nor'easter 2 and Columbus Nor'easter, also had pre-storm water level anomalies, but to a slightly lesser degree than the two storms listed above. By accounting for the pre-storm anomaly, it was shown that storm surge levels were actually lower the reference surge because part of what was considered surge was actually anomaly. Nonetheless, water levels were elevated and produced substantial flooding in the LCB.

Analysis of maximum observed and potential water levels provided an interesting insight into what level the water could have reached during each storm if the maximum water level occurred at low or high tide. It was shown that the maximum storm surge for Hurricane Isabel did occur near high tide at all stations, which could partially describe why it produced some of the highest water levels ever reached during the last thirteen years at most stations, only falling second to Nor'Ida at some of these stations. In addition to potential water levels for each storm using a time-shift, a thirteen-year 
potential maximum was calculated for each station using the worst conditions out of all eleven storms. Results of the thirteen-year potential maximum show that the worst may still be to come. For each station, the maximum observed level ever reached within the thirteen-year time span ranged from $0.5 \mathrm{~m}$ to $0.3 \mathrm{~m}$ away from the potential maximum. This suggests that if a storm arrives at high tide with a significant anomaly present and the right storm conditions (wind speed, direction, storm track, etc.), all of the stations analyzed in this study could see extreme flooding that surpasses what has been seen within the past few decades. Furthermore, with the impending threat of sea level rise in this area, the worst is likely still to come. However, coastal planners and emergency personnel can use the results of this study to prepare local communities for potentially destructive storms in the future. 
Figures and Tables

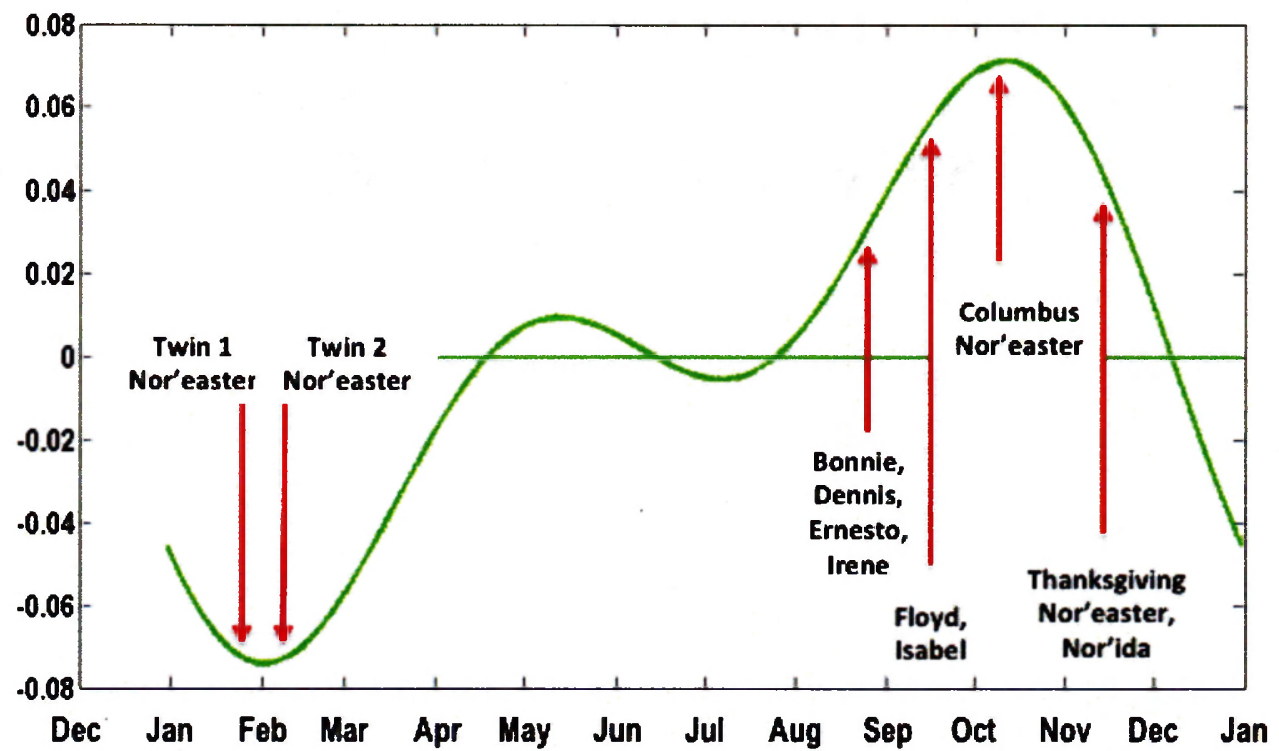

Figure 2.1: A conceptual graph of the average seasonal cycle and where each of the eleven storms fell during the cycle. 


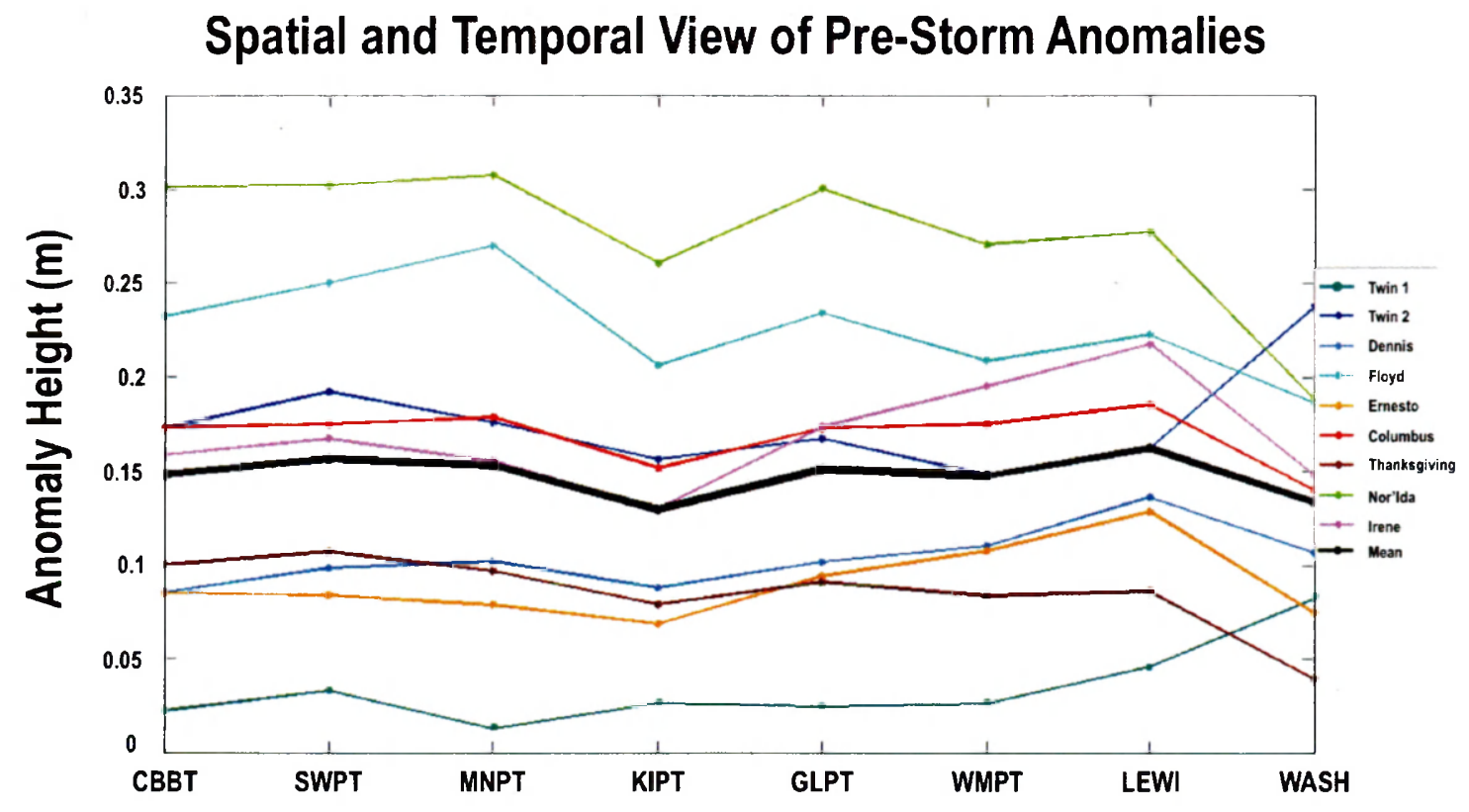

Figure 2.2: Anomaly values for each storm at each station. Anomalies varied by storm (colored lines), but did not display much spatial variability. 

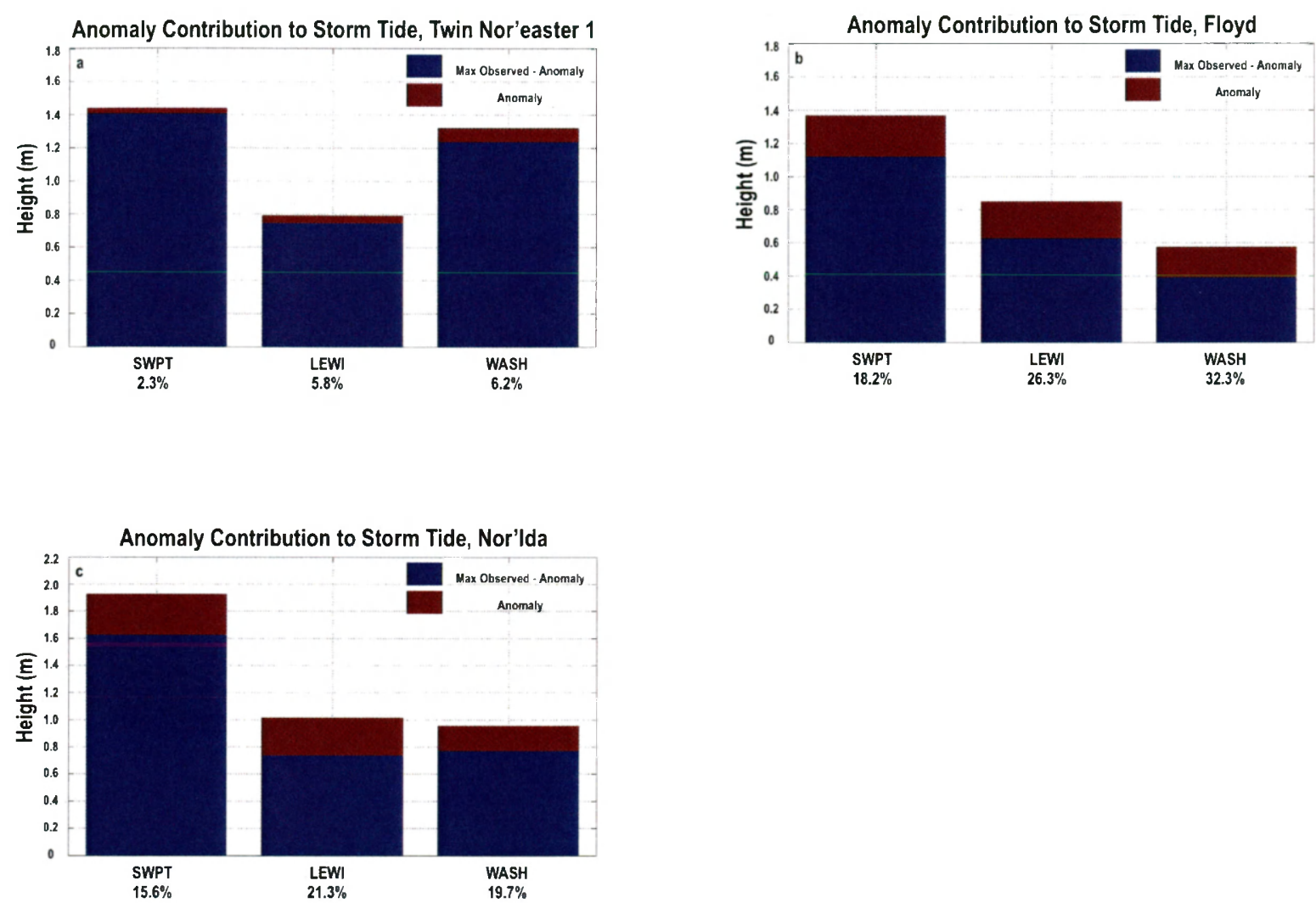

Figure 2.3 (a-c): Anomaly contribution to storm tide in both value and percentage for three stations during Twin Nor'easter 1 (a), Hurricane Floyd (b), and Nor'Ida (c). 

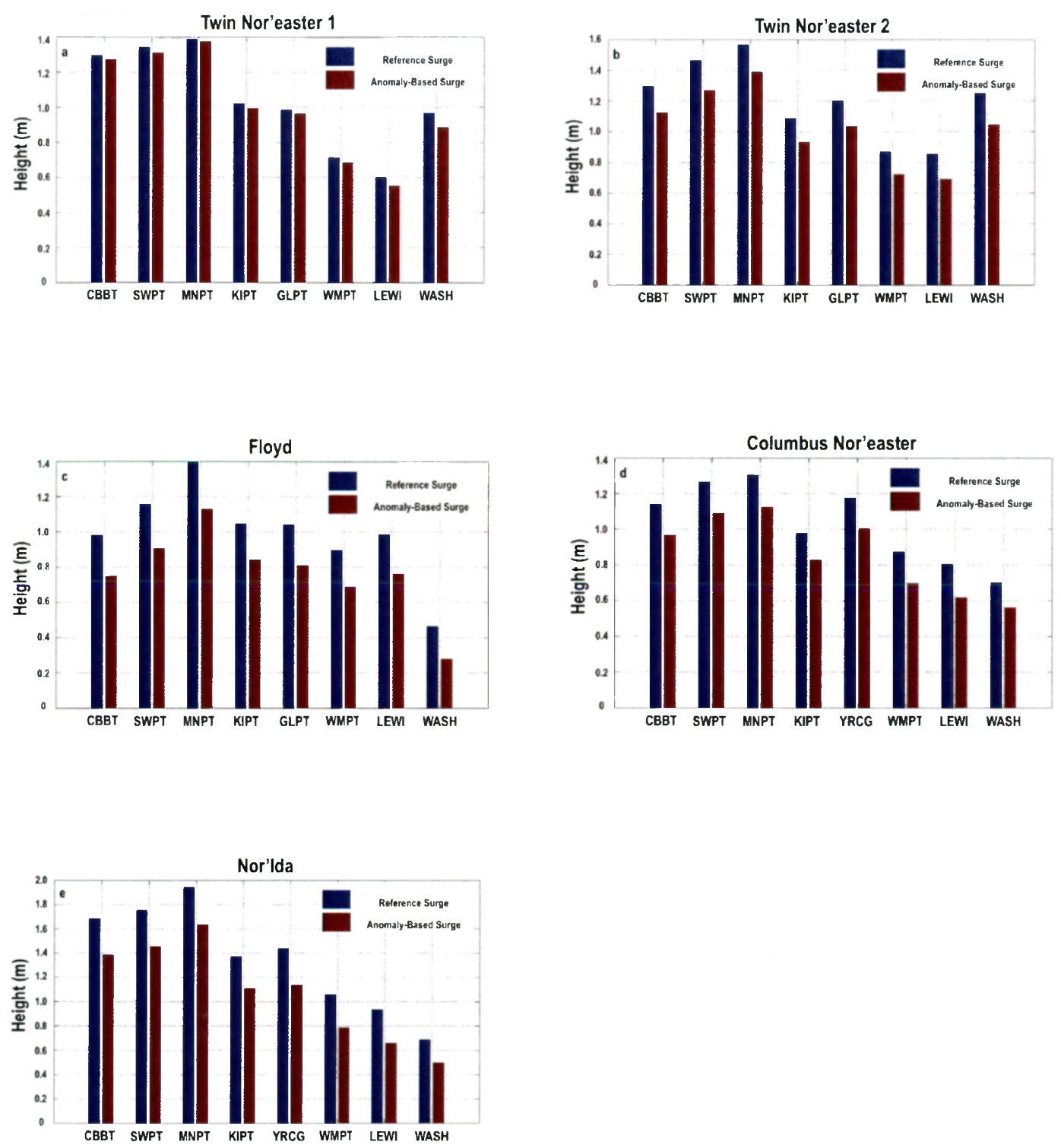

Figure 2.4 (a-e): Storm surge values using both the Reference surge (Eq 2.5, blue) and the anomaly-based method (Eq 2.4, red). During this set of storms, the anomaly-based method produced surges that were lower than the Reference surges. 

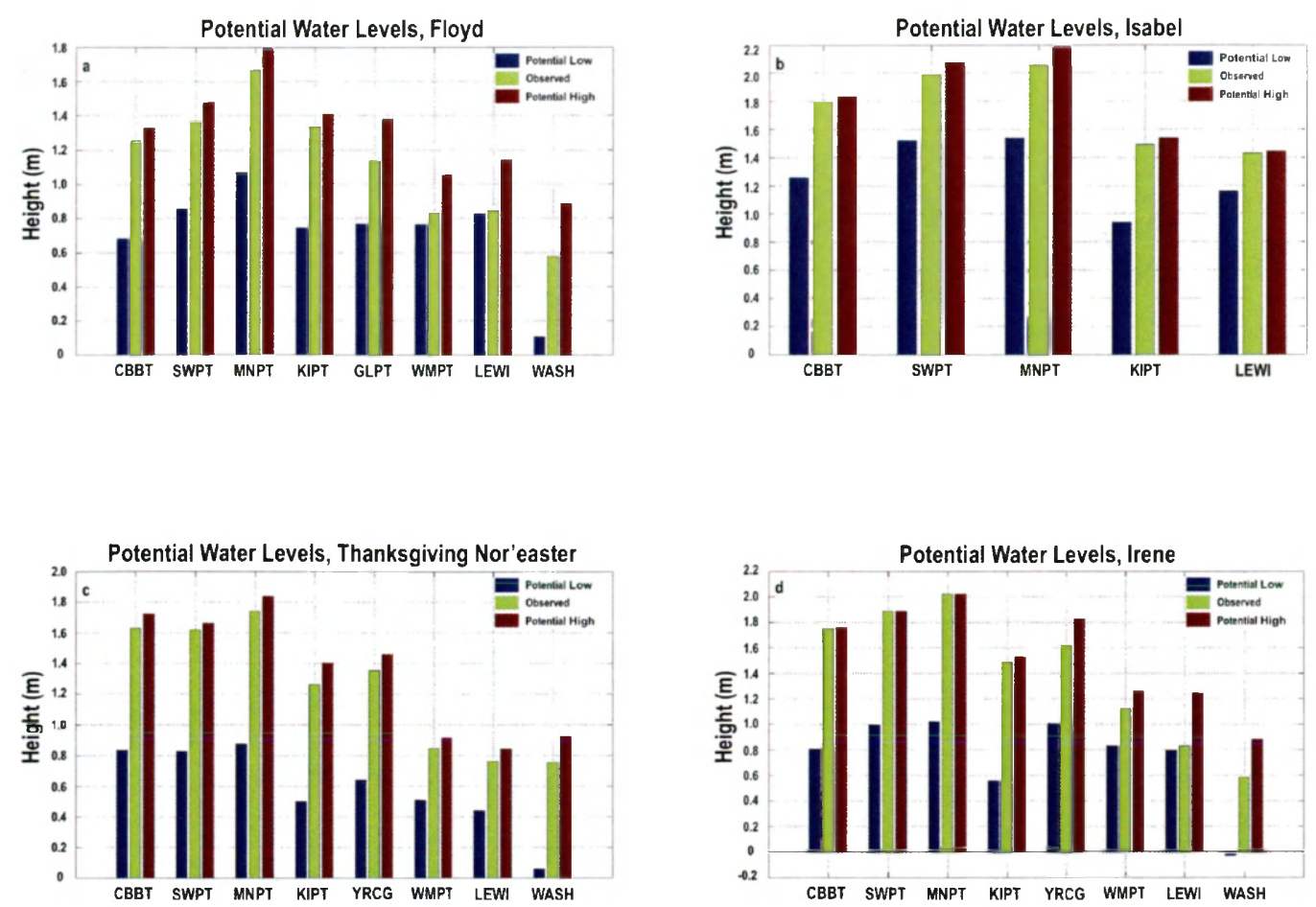

Figure 2.5 (a-d): The potential low and potential high water levels, as well as the maximum observed for Hurricane Floyd (a), Hurricane Isabel (b), Thanksgiving Nor'easter (c), and Hurricane Irene (d). 


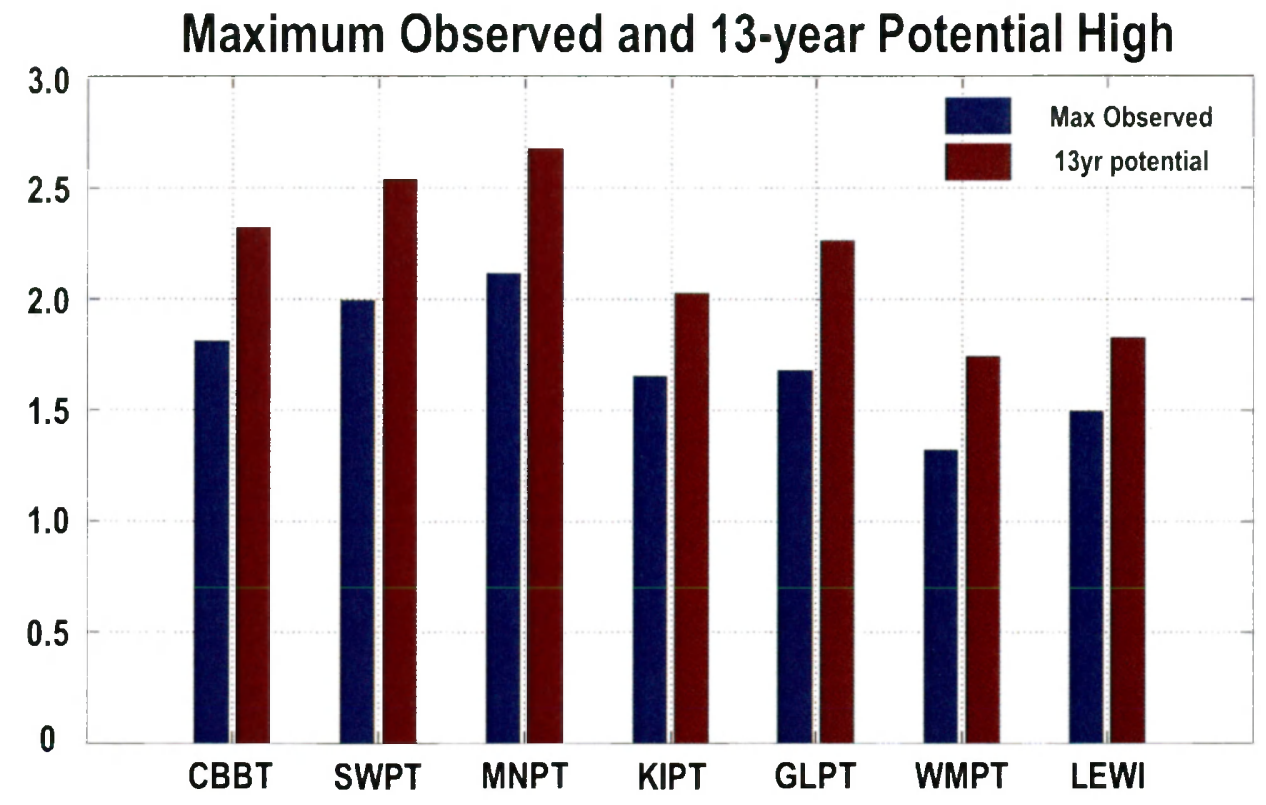

Figure 2.6: Maximum observed water level out of all storms and the 13-year potential high for each station. 
Table 2.1: Difference between maximum observed and 13-year potential high:

\begin{tabular}{|l|l|l|l|l|l|l|}
\hline CBBT & SWPT & MNPT & KIPT & GLPT & WMPT & LEWI \\
\hline 0.5079 & 0.5419 & 0.5596 & 0.3768 & 0.5849 & 0.4168 & 0.3353 \\
\hline
\end{tabular}




\section{References}

Boon, J. D. (2004). Secrets of the tide: Tide and tidal current analysis and applications, storm surges and sea level trends. (p. 134). Cambridge, UK: Woodhead Publishing Limited.

Boon, J.D. Sea Level rise and the Impact of Lesser Storms. Workshop on Sea Level Rise and Coastal Infrastructure: Predictions, Risks and Solutions sponsored by the University of Maryland and the American Society of Civil Engineers, Reston VA, June 9-10, 2012. Invited paper submitted for publication in ASCE Monograph (B.M. Ayyub, M. Kearney eds).

Carter, H. H. and D. W. Pritchard (1988). Oceanography of Chesapeake Bay. In B. Kjerfve (ed.), Hydrodynamics of Estuaries, 2. Estuarine Case Studies. CRC Press, Boca Raton, Florida, pp. 1-16.

De Lange, W. P., \& Gibb, J. G. (2000). Seasonal, interannual, and decadal variability of storm surges at Tauranga, New Zealand. New Zealand Journal of Marine and Freshwater Research, 34, 419-434.

Flather, R. A. (2009). Storm surges. In J. H. Steele, S. A. Thorpe \& K. K. Turekian (Eds.), Elements of Physical Oceanography (p. 77). London, UK, Burlington, MA, San Diego, CA: Academic Press. 
Goring, D. G. (1995). Short-term variations in sea level (2-15 days) in the New Zealand region. New Zealand Journal of Marine and Freshwater Research, 29, 69-82.

Kleinosky, L. R., Yarnal, B., \& Fisher, A. (2007). Vulnerability of Hampton Roads, Virginia to storm-surge flooding and sea-level rise. Natural Hazards, 40, 43-70.

Sweet, W., Zervas, C., \& Gill, S. U.S. Department of Commerce, National Oceanic and Atmospheric Administration, National Ocean Service. (2009). Elevated east coast sea levels anomaly, june-july, 2009 (NOAA Technical Report NOS CO-OPS 051). Silver Spring, Maryland: Center for Operational Oceanographic Products and Services. 
Chapter 3

Spatial and Temporal Variability of Storm Tide Components and the Use of Tidal Datums 


\section{Abstract}

Spatial and temporal variations of storm tide components were identified in this study. It was found that the anomaly component did not vary spatially, but displayed considerable variability from storm to storm. Storm surge exhibited a spatial trend of Central Bay stations having smaller maximum surge values than most South Bay stations, with the exception of Kiptopeke. Surge also varied by storm. The tidal range was graphed and displayed a trend of South Bay stations having larger tidal ranges than Central Bay stations. Maximum storm tide values were assessed relative to two tidal datums, mean lower low water (MLLW) and highest astronomical tide (HAT). Results show that HAT could be a good indicator of flooding impact. Finally, the area under the storm tide curve, or integrated intensity (relative to HAT) was computed and trends were identified. Integrated intensity displayed substantial variability between storms, while spatial variability depended on the given storm. Spatial trends in storm tide components and integrated intensity were further quantified and verified using Principal Component Analysis.

\subsection{Introduction}

When assessing storm tides in the Lower Chesapeake Bay (LCB), the datum, or reference level, is an important factor to consider. NOAA defines several datums, falling under the category of either tidal datum or geodetic datum. Tidal datums, such as mean lower low water (MLLW), mean sea level (MSL), and highest astronomical tide (HAT) are used in this study. MLLW is defined as the average of the lower low water height of each tidal day observed over the National Tidal Datum Epoch (NTDE). MSL is the mean of hourly water heights observed over the NTDE. HAT is the elevation of the highest 
predicted astronomical tide expected to occur at a specific tide station over the NTDE. Reporting, and sometimes ranking, storm tides relative to MLLW is common. However, water level at a given height above MLLW at a large-range location may have relatively low impact compared to the same height above MLLW at a small-range location. Therefore, HAT should be explored as an alternative.

This chapter addresses multiple issues relating to storm tides, including 1) the spatial variability of storm tide components throughout the $L C B, 2$ ) the use of different tidal datums to assess the impact of overall storm tide at different locations in the LCB, and 3) the spatial and temporal variability of integrated intensity, or area under the storm tide curve. The first section expands on the results from chapter two, where individual storm tide component contributions were quantified. These components will be assessed for spatial and temporal trends. The second and third sections use multiple methods to explore using HAT as storm impact metric. The goals of this study are to address the following questions:

1. Do individual components of storm tide vary spatially throughout the LCB?

2. Does the use of HAT provide more information about potential flooding than MLLW when assessing extratidal water levels?

3. Do extratropical and tropical systems differ in their integrated intensity values on spatial and temporal scales?

\subsection{Methods}

\subsubsection{Principal Component Analysis (PCA)}

It is important to not only understand the variability of storm tide itself, but also variability of the individual components. Principal Component Analysis (PCA) is one 
method of examining structures of variability. PCA is a commonly used multivariate technique that aims to reduce the dimensionality of a data set. It transforms highly correlated variables from an original data set into new sets of uncorrelated variables, called principal components (PCs) or modes, which retain most of the original information.

The "princomp" command in MATLAB performs PCA on data matrix, X. [coeff, score, latent] $=\operatorname{princomp}(X)$ Eq. 3.1 Coeff gives the coefficients of the principal components (PCs), which are the eigenvectors of the covariance matrix. Score is the representation of the original data matrix, $\mathrm{X}$, in the principal component space. Latent provides the eigenvalues of the covariance matrix. Ordering the eigenvalues from highest to lowest gives the components in order of significance. Adding all of the eigenvalues together gives the total variance.

PCA was used to analyze spatial trends about the mean for the local anomaly, maximum storm surge, and integrated intensity. As a reminder, the local anomaly and maximum storm surge data are relative to MSL, while integrated intensity is expressed relative to HAT. Standardizing the data is an important step to take if different variables have different units (Martinez \& Martinez, 2005). However, none of the data matrices in this study required standardization because all values within a given matrix had the same units. MATLAB's "princomp" command (Eq. 3.1) was used to run the PCA. Using the "latent" outcome, the percent of variance explained by each mode was calculated as:

$$
\text { percent_explained }=100 * \text { latent } / \text { sum(latent }) \quad \text { Eq. } 3.2
$$

Calculating the percent variance by each PC allows for a clear view of which PCs are most important. If most of the variance of a data set can be explained in just a few PCs, 
the remaining PCs can be discarded. Scree plots are useful in determining how many PCs to retain. The eigenvalues are plotted for each PC and the "elbow" point is determined. A steep slope, followed by a leveling out of the values, characterizes the "elbow" point. Similar to the scree plot is the pareto plot. The percent of variance for each PC is calculated and plotted as a bar graph, in order of decreasing variance.

\subsubsection{Storm Tides Relative to Highest Astronomical Tide}

To find the number of hours above HAT for each storm, a time window was defined at each station. The date that the water levels first exceed HAT marks the beginning of the time window. The end date is dependent upon several factors. In some instances, water levels fell below HAT within hours of the storm passing. In other cases, water levels remained high for several days after the storm. If the second scenario occurred, then weather conditions, such as wind speed and direction and precipitation were checked to ensure that another weather system hadn't moved into the area, keeping the water levels high. Then, the water levels had to meet a condition of falling below HAT and remaining there for at least two tidal cycles. The end of the time window was selected as the date this condition was met.

The maximum water level relative to MLLW was determined for each storm at each station. Then HAT was subtracted from the maximum water levels to determine the maximum height above HAT. The maximum height relative to MLLW and HAT for each station and storm was ranked for comparison.

\subsubsection{Integrated Intensity}


For each storm at each station, the integrated intensity, or the area under the storm tide curve, was found by integrating the height above HAT over the time period of the storm (Eq. 3.3).

$$
\text { Area }=\int_{t 1}^{t 2} f(t) d t \quad \text { Eq. } 3.3
$$

Where $f$ is the total height minus HAT and the integration includes only the time segments where height exceeds HAT. Results from integrated intensity were visually analyzed for spatial trends, and then PCA was used to statistically test the results.

\subsection{Results}

\subsubsection{Spatial Variations of Storm Tides and Individual Components}

Two of the individual storm tide components, predicted tide and storm surge, varied spatially throughout the LCB, while the local anomaly was spatially uniform. Though the anomaly did not vary spatially, there was considerable variability from storm to storm. Nor'Ida and Hurricane Floyd had the highest pre-storm anomaly values of all the storms, while Twin Nor'easter 1 had the lowest values (Figure 3.1). Anomalies for all of the storms in this set were positive, indicating average water level over the 30 days preceding each storm was above mean sea level at each station. These results were further quantified through the use of Principal Component Analysis (PCA). Ninety-five percent of the variance within the anomaly data was described by mode 1 (Figure 3.2). As displayed in Figure 3.2a, mode 1 (blue) shows very little variation throughout the set of stations. Mode 2 (green) is relatively unimportant because it only describes three percent of the variance; however, it does come into play for Twin Nor'easter 2. If we view the scores of each mode over the storm series we can see the role that each mode plays during each storm (Figure 3.2b). Since PCA is showing variance about the mean, 
viewing the role of each mode during each storm should point out the same trend seen about the mean shown in Figure 3.1. Twin Nor'easter 1 had a strong negative score, which indicated that the anomaly was well below the mean, corresponding to a very small positive value during this storm. Hurricane Dennis, Tropical Storm Ernesto and the Thanksgiving Nor'easter all had slightly negative scores, indicating that the anomaly was small, but still larger than Twin Nor' easter 1. Scores were positive and smallest in magnitude for Twin Nor'easter 2, the Columbus Nor'easter and Hurricane Irene, meaning the anomaly was near or slightly above the mean value for these storms. Finally, Hurricane Floyd and Nor'Ida had strong positive scores, meaning that the anomaly values were highest of all during these storms.

Storm surge exhibited spatial variability, which can be seen in the raw data (Figure 3.3). There is a trend of the Central Bay stations having smaller maximum storm surge values than the South Bay station. The mean surge at Kiptopeke is considerably lower than that of Money Point, which had the largest value of all stations. PCA was used in two ways to analyze maximum storm surge data. First, PCA was applied to all of the stations and storms. Two potential outliers were identified, which were Tropical Storm Ernesto and Washington. PCA was applied to a new data matrix that excluded data from Ernesto and Washington. Results from the PCA applied to the original data set will be presented first.

Three modes were identified from the PCA of the original dataset. Mode 1 accounted for fifty-one percent of the variance and displayed a structure where there was a slight increase in the coefficient from South Bay to Washington. Mode 2 accounted for twenty-eight percent of the variability and had a magnitude at Washington much larger 
than at all other stations. Finally, mode 3 accounted for only nineteen percent of the variability. In this mode, coefficient values were negative for Chesapeake Bay Bridge Tunnel, near zero for Sewells Point, Money Point and Kiptopeake, increasing from there to the north to Lewisetta, and sharply decreasing for Washington (Figure 3.4a).

Mode 1 dominated during Tropical Storm Ernesto, the Columbus and Thanksgiving Nor'easters with little influence from the other modes; however, Ernesto displayed a positive signal while the nor'easters displayed a negative signal, indicating that stations were mainly above the mean for Ernesto and below the mean for the two nor'easters (Figure 3.4b). The rest of the storms displayed some combination of modes. For example, Hurricane Floyd was influence mostly by mode 1, with some influence from mode 3 . The fact that multiple modes can influence any particular storm makes the story a bit complex, but ultimately the trends lie within the raw data, as seen in Figure 3.3 .

As mentioned above, a second test was applied to the maximum surge data excluding tropical Storm Ernesto and Washington. The raw data showed a much smoother trend of maximum surges throughout the LCB (Figure 3.5), in which maximum surge height generally decreased from South to Central Bay stations, with some deviation. PCA was applied to this second dataset. By removing the two outliers, the PCA was able to decrease the number of modes with most of the variance from three to two. Mode 1 (seventy-eight percent of variability) exhibited a similar, but opposite trend to Mode one of the analysis on the original data. Where the previous structure showed a slight increase in the coefficient from South Bay to Washington, the structure excluding the two outliers showed a slight decrease in the coefficient from South Bay to Central 
Bay (Figure 3.6). Mode 2 (seventeen percent of variability) of this test was very similar to mode 3 of the previous test, excluding Washington (Figure 3.6a). Nor'Ida strongly exhibited mode 1 and had a positive score, indicating that all of the stations were above the mean. Hurricanes Dennis and Floyd both had a strongly negative score for mode 1, meaning that the surge values for all stations were below the mean (Figure 3.6b).

The last of the storm tide components, the predicted tide, exhibited considerable spatial variability, as seen in Figure 3.7. The great diurnal tidal range, which is the difference in height between Mean Higher High Water (MHHW) and Mean Lower Low Water (MLLW), is used to quantitatively describe the tides in the LCB. Money Point $(0.98 \mathrm{~m})$ and Washington $(0.97 \mathrm{~m})$ have the largest tidal range while Windmill Point $(0.42 \mathrm{~m})$ and Lewisetta $(0.46 \mathrm{~m})$ have the smallest range.

\subsubsection{Using HAT vs. MLLW}

A pattern exists that central bay stations spend more hours above HAT than South Bay stations and Washington. On a cumulative basis over the 13-year period, water levels at Windmill Point and Lewisetta were higher than HAT much longer than the other stations in the LCB (Figure 3.8). In Figure 3.9, time series of annual values of hours above HAT maintain the same general relative ranking of stations throughout the period, but exhibit considerable interannual variability. This pattern of longer duration above HAT for the Central Bay stations applied as well for individual storms (Figure 3.10). Figure 3.8 shows that Washington behaved similarly to the South Bay stations, but had a slightly larger number of hours above HAT over the study period. Figure 3.9 further describes Washington's deviation from the south bay stations for individual years between 1996 and 2011. 
Maximum height above MLLW for each storm at each station (Figure 3.11)

reveals a trend of South Bay stations having larger maximum heights than central bay stations. Washington is inconsistent between storms. The maximum height above HAT for each storm at each station is shown in Figure 3.12. Similar to the results for maximum height above MLLW, Central Bay stations appear to have smaller maximum heights above HAT than South Bay stations. However, the difference in height above HAT between the Central Bay and South Bay stations is reduced. Washington does not display a clear pattern in maximum height above HAT. For some storms it behaves similar to South bay stations and for other storms it is not similar to other stations. By ranking each station in terms of maximum height above MLLW and HAT and taking the difference between the two, it was determined that South Bay stations generally went down in rank while Central Bay stations went up in rank. This pattern is most apparent for Tropical Storm Ernesto, where Central Bay stations were originally ranked with the lowest maximum heights relative to MLLW, but were ranked with the highest maximum water levels relative to HAT (Table 3.1). This pattern of higher rankings for Central Bay stations relative to HAT is apparent to a much lesser degree in other storms, such as the Columbus Nor'easter (Table 2).

\subsubsection{Integrated Intensity}

Figure 3.13 points out spatial and temporal trends in integrated intensity. There is evidence of spatial variability during all storms except for Hurricanes Floyd and Irene, and Twin Nor'easter 1 . However, the means for each station are not much different from one another. Between storms, integrated intensity varied substantially. Twin Nor'easter 2 and Nor'Ida had the highest integrated intensities of all storms. Hurricanes Floyd and 
Irene had the lowest integrated intensity values of all storms, and did not exhibit much spatial variability. Principal Component Analysis was used to further quantify spatial and temporal variability of integrated intensity relative to the mean at each station. Ninetytwo percent of the variability within the data was described by mode 1 (Figure 3.14), while mode 2 only described five percent of the variance. Mode 1 describes all stations as similar, meaning that all stations are either above or below the mean. This does not mean that spatial variability isn't present; it is simply relating the variance to the mean spatial pattern. Twin Nor'easter 1 and the Thanksgiving Nor'easter 2 both exhibited slightly negative scores, meaning the integrated intensity values were just below the mean. Hurricanes Floyd and Irene had strongly negative scores, indicating that the integrated intensity values were far below the mean. Hurricane Dennis and the Columbus Nor'easter had slightly positive scores, meaning integrated intensity values were just above the mean. Twin 2 and Nor'Ida had strongly positive scores, indicating that integrated intensity values were all high above the mean (Figures 3.14b). Mode 2 shows South Bay stations below the mean and Central Bay stations and Washington as above the mean (Figure 3.14a). As indicated by the scores for this mode, its north-south variation appeared in the spatial patterns of Twin 2 and Ernesto and, in the opposite sense, in Nor'Ida. However, only for Ernesto was the influence of mode 2 stronger than mode 1. Results from the PCA help elucidate the trends seen in Figure 3.13.

\subsection{Discussion}

\subsubsection{Identifying Spatial Trends in Storm Tide Components}

Storm tide consists of three components: the predicted tide, storm surge and the local anomaly. One of the goals of this chapter was to quantify the spatial aspect of storm 
tide components. Anomalies did not vary spatially, but displayed extensive variance among storms. The local anomaly, relative to the tides and storm surge, is a long-term phenomenon that can occur on a scale of one week to several months. This longer time scale may explain the uniformity of the anomaly throughout the LCB. Since the anomaly occurs on a longer time scale, water levels in the LCB are thought to slowly rise as a whole, and fall as a whole, giving the bay time to adjust to these changes. This is unlike the tides, which occur on a much shorter scale. The spatial variability in the tides is due to a mixture of physical features and processes, such as the size and shape of the bay. Storm surge is heavily dependent upon storm conditions, such as wind speed and direction, storm track, inverse barometer, precipitation and wave setup. In the case of tropical systems, storm track plays a particularly important role in storm surge levels. The counterclockwise rotation around the center of low pressure can pull water away from some areas and cause setup in other locations, depending where the storm center is located in relation to the Chesapeake Bay. Tropical Storm Ernesto is one example where winds may have pulled water away from the South Bay stations and produced setup at the Central Bay stations.

\subsubsection{Moving Toward the Use of HAT}

Central bay stations spend more hours above HAT than South Bay stations and Washington, which may be partially attributed to tidal range. The South Bay stations and Washington have larger tidal ranges than the central bay stations; therefore, central bay stations may exceed HAT more often. Washington has one of the largest tidal ranges of all the stations in this study (Carter and Prichard, 1988); however, it does not always follow the same pattern as other large-tidal range stations. For instance, as shown in 
Figure 3.9, near the beginning and end of the study period Washington spent more hours above HAT than the South Bay stations whereas in general, from $~ 1999-2009$, Washington fell within the limits of the other large tidal range stations.

Maximum heights above both MLLW and HAT appear to be smaller at the central bay stations than at the south bay stations. Washington does not follow this pattern. In fact, maximum heights for Washington may be higher than the central bay stations when relative to MLLW, but smaller than central bay stations when relative to HAT. This is evident during several storms. When comparing Washington to the Central Bay stations, it appears that a difference in tidal range explains part of this variation. However, when comparing the Central Bay stations and the South Bay stations, tidal range may play a lesser role and characteristics of the storm itself may play a larger role.

When stations are ranked in terms of their maximum water levels reached relative to MLLW and HAT, it can be seen that Central Bay stations often move up in rank, suggesting a greater impact than originally seen when using MLLW. This implies that HAT may be more useful datum than MLLW when assessing storm tide impact. Since HAT is the highest predicted tide expected to occur during the National Tidal Datum Epoch (NTDE), observing water levels that surpass HAT will give an estimate of flood impact, whereas MLLW cannot be easily used for this purpose because water levels are almost always above MLLW.

\subsubsection{Spatial and Temporal Trends in Integrated Intensity}

The integrated intensity metric combines the magnitude of storm tide heights above HAT with the duration at elevated levels. The definition of this metric may lead one to think that storm type would play a major role in integrated intensity value, with 
longer-duration nor'easters potentially having larger values of integrated intensity. This trend is indeed present at most stations (Figure 3.13). Nor'Ida and Twin Nor'easter 2 have the highest integrated intensity values at all stations, except for Washington. All nor'easters had higher integrated intensity values than the tropical systems, with two exceptions. Hurricane Dennis had the third highest integrated intensity value, but this can be described by the unusually long duration of the storm. Dennis had an unusual storm track, where it travelled up the East Coast of the U.S. and while off the coast of North Carolina, backtracked south, and then progressed toward east-central North Carolina and up through the western portion of Virginia. Therefore, the Chesapeake Bay experienced the effects of Hurricane Dennis for an extended period of time, like a nor'easter. The second exception is Tropical Storm Ernesto. This storm had low integrated intensity values for the South Bay stations, which follows the other tropical systems, but large values for the Central Bay stations. A potential explanation for this deviation from other tropical systems lies within the storm track. The position of Tropical Storm Ernesto over Virginia suggests that winds were pushing water away from the South Bay stations and toward the Central Bay stations. Additionally, Ernesto gained extratropical properties by the time it arrived at the North Carolina/Virginia boarder, and slowly progressed north (NOAA Tropical Cyclone Report, 2006).

Integrated intensity varied spatially within most storms; however, this trend was not as apparent when viewing the mean of all storms combined for each station. In general, storms with lower integrated intensity values exhibited less spatial variability, and vice versa. In terms of this study, most of the extratropical systems and storms that gained extratropical properties, such as Hurricane Dennis and Tropical Storm Ernesto, 
exhibited spatial variability while tropical systems did not show much variation, though this was not always the case, especially for Twin Nor'easter 1 . Though trends were revealed within the storms used in this study, a detailed analysis of more storms and stations is needed before making further conclusions.

\subsection{Conclusions}

Analysis of individual storm tide components revealed that the anomaly is spatially uniform, while the storm surge and predicted tide exhibit spatial variability. Storm surge is the component that people are most concerned with because out of all the components, it contributes the most to overall storm tide. It is apparent that the position of the center of some storms relative to the LCB can cause deviations from the normal spatial trends of storm surge. This is true for Tropical Storm Ernesto, where wind were pulling water away from the South Bay stations and pushing water toward Central Bay stations

It is common to report water levels in terms of MLLW. However, it is difficult to determine storm impact from viewing height above MLLW because water levels are usually above MLLW. HAT provides a more consistent view of storm impact because water levels are not expected to exceed HAT under normal weather conditions. Referencing the maximum storm tide relative to HAT could be helpful to local communities. For instance, if exceeding HAT by $0.5 \mathrm{~m}$ would cause extensive flooding in some areas, forecasters could more easily predict areas that require evacuation during a large storm. Integrated intensity is an additional way of viewing storm impact. This metric quantifies differences between tropical and extratropical systems in terms of the impact of storm duration and height above HAT. By understanding the integrated 
intensity of different storm types, it may be possible to predict how long certain areas will be inundated after a storm has passed.

Results presented in this chapter show that spatial variability exists in maximum surge, the predicted tide, storm tide height above HAT, hours above HAT, and integrated intensity. Relative sea level rise rates also vary within the bay (Boon et al, 2010; Ezer and Corlett, 2012). With sea level rising throughout the bay the overall impact of a given storm will certainly be worse in all of these locations. Installing more tide gauges in the Central Bay area and on the Eastern Shore of Virginia could provide an even better understanding of spatial trends in the LCB. 
Figures and Tables

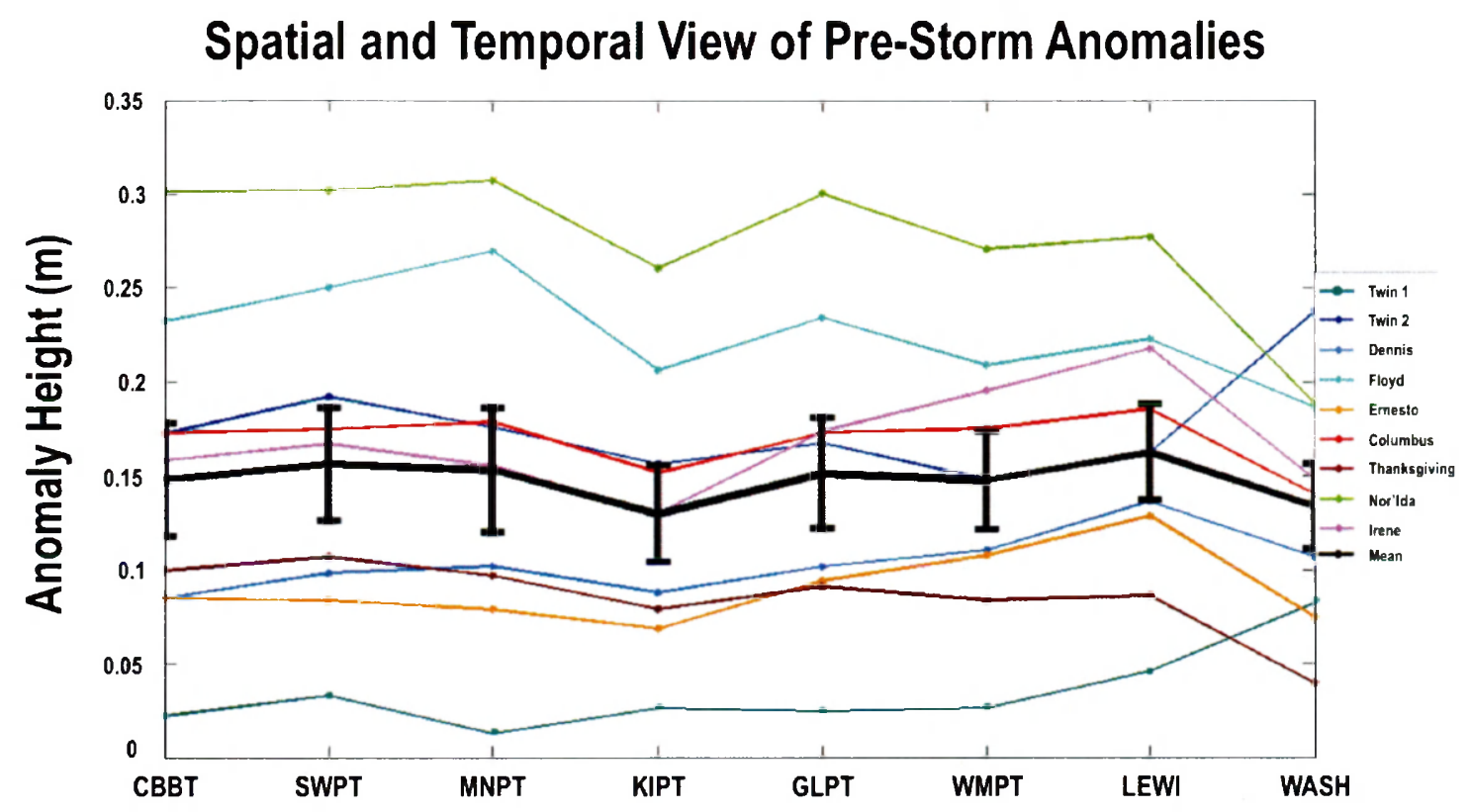

Figure 3.1: Anomaly values for each station during each storm. The mean (black) of all storms for each station is plotted and error bars represent standard error. 


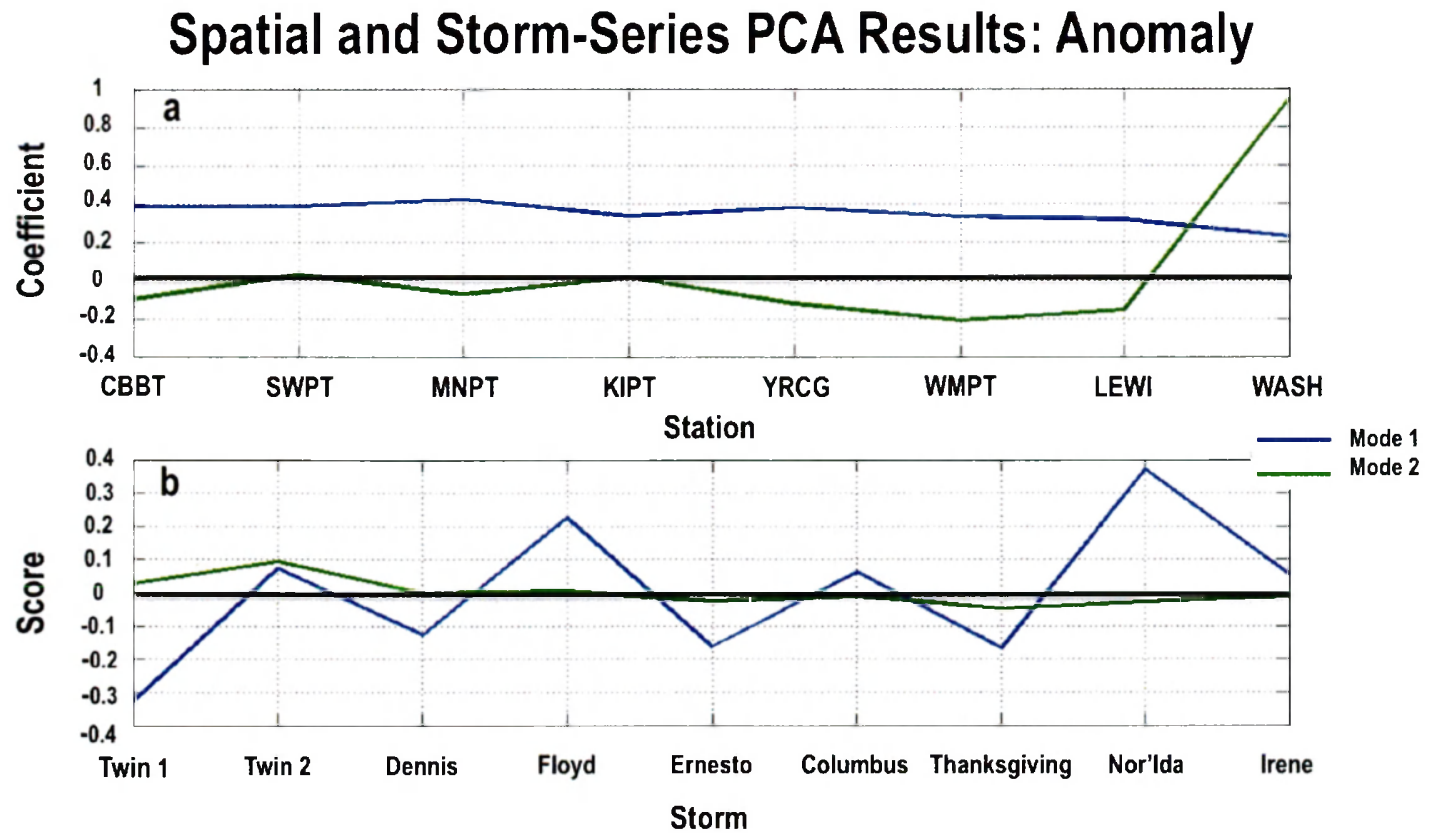

Figure 3.2: PCA outcome for the local anomaly. The two important PCs, are shown for each station (a). Part (b) shows the influence of each mode during these nine storms. 


\section{Spatial and Temporal View of Maximum Surge}

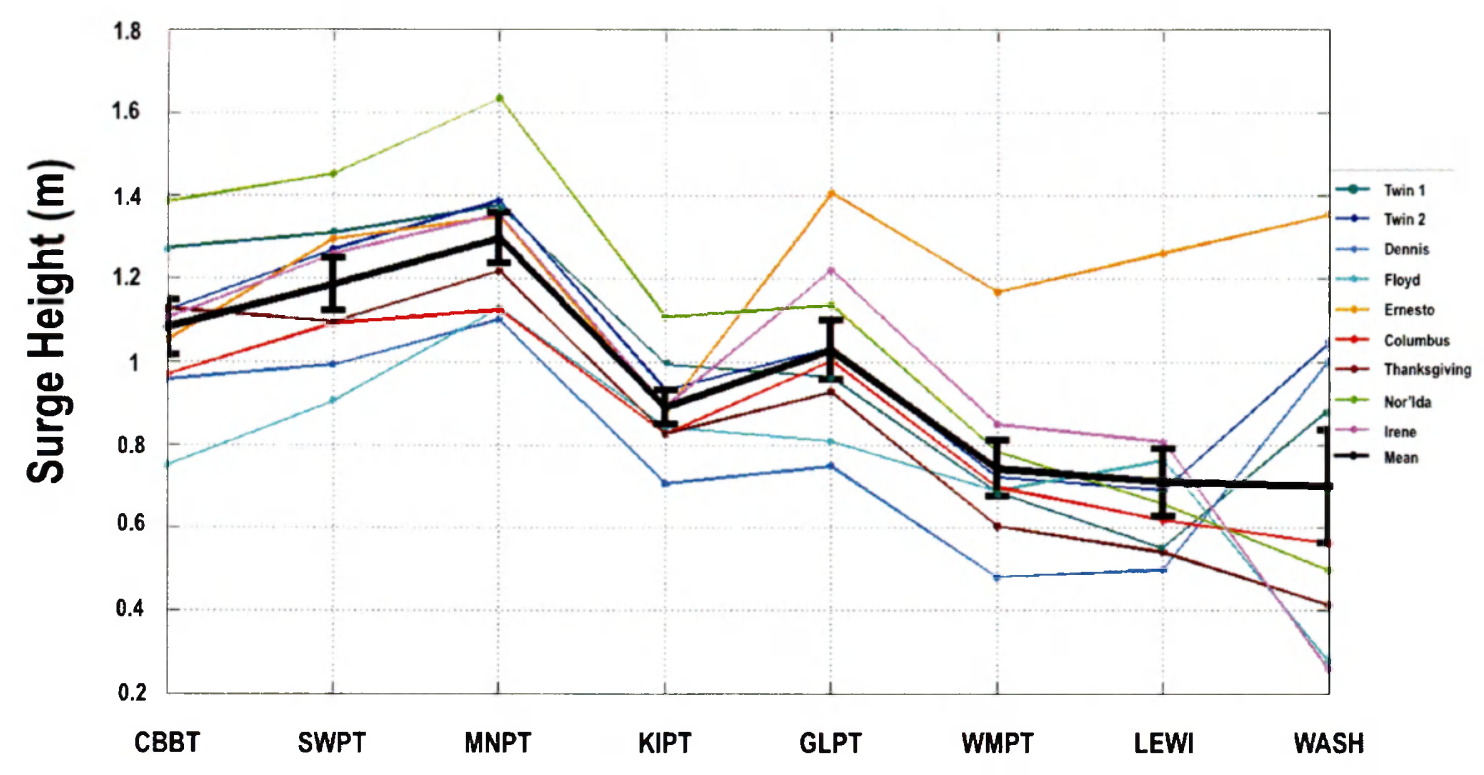

Figure 3.3: Maximum surge values for each station during each storm. The mean (black) of all storms for each station is plotted and error bars represent standard error. 


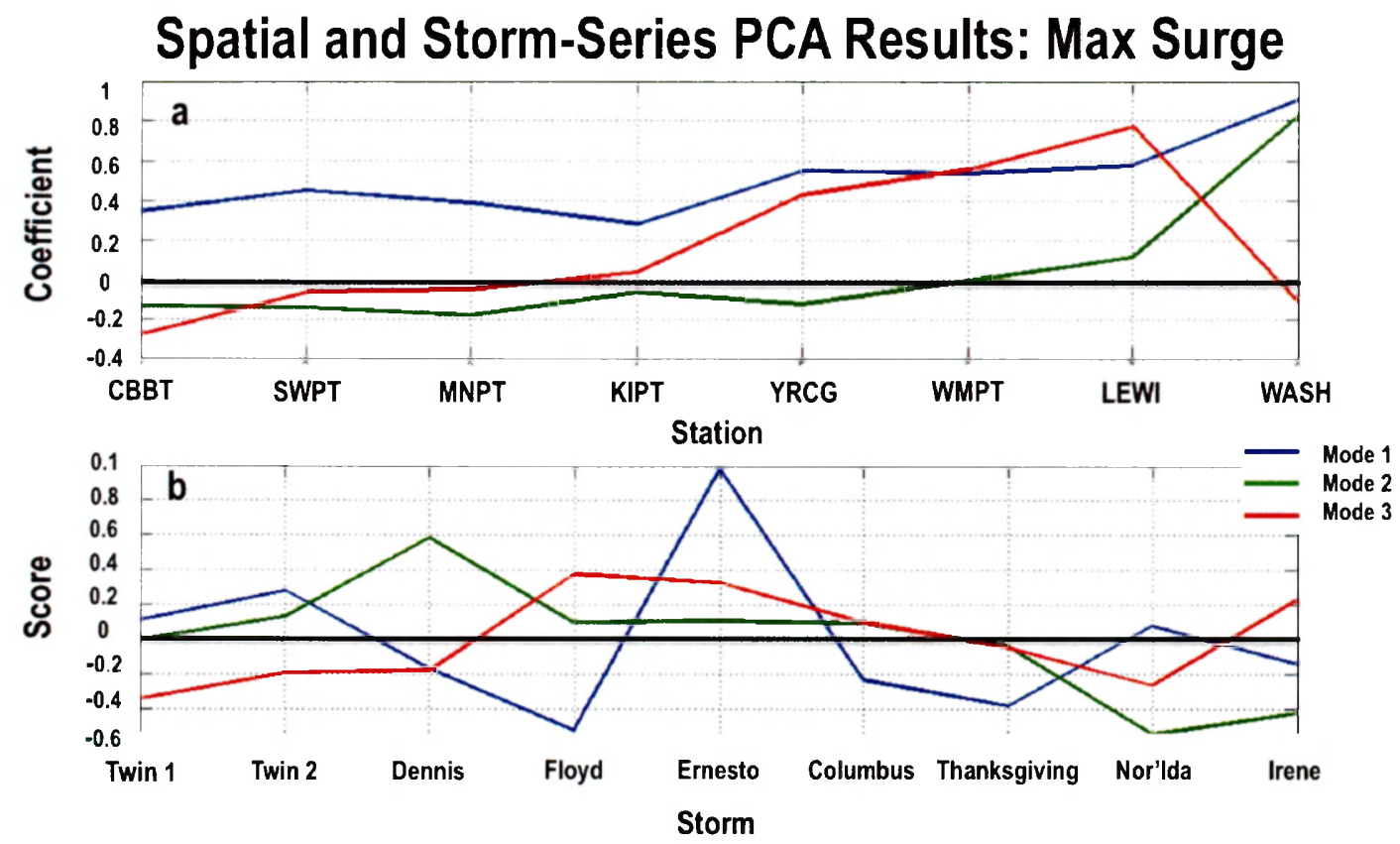

Figure 3.4: PCA outcome for maximum storm surge. The three important PCs, are shown for each station (a). Part (b) shows the influence of each mode during these nine storms. 


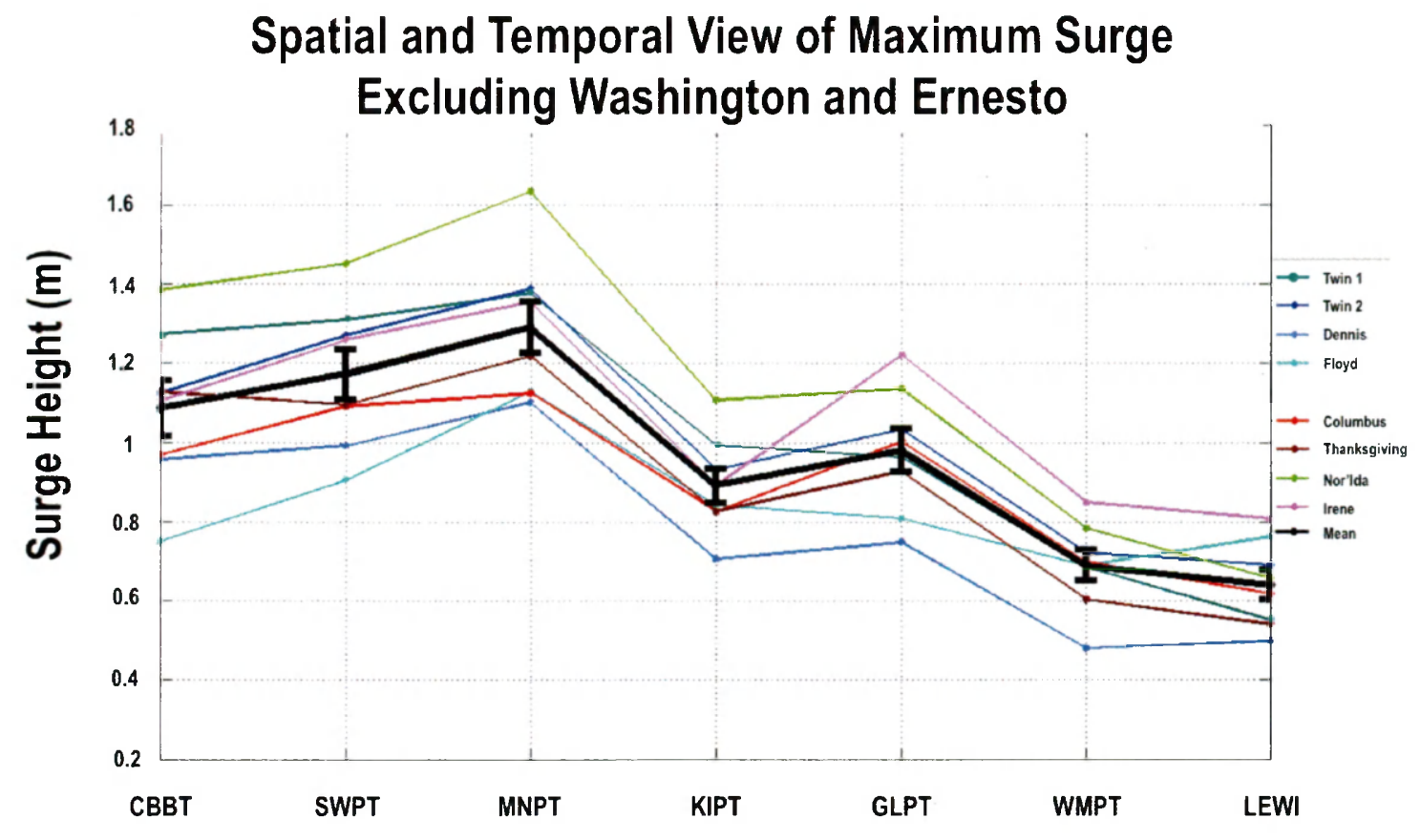

Figure 3.5: Maximum surge values, excluding Washington, D.C. and Tropical Storm Ernesto. The mean (black) of all storms for each station is plotted and error bars represent standard error. 


\section{Spatial and Storm-Series PCA Results: Max Surge Excluding Washington and Ernesto}

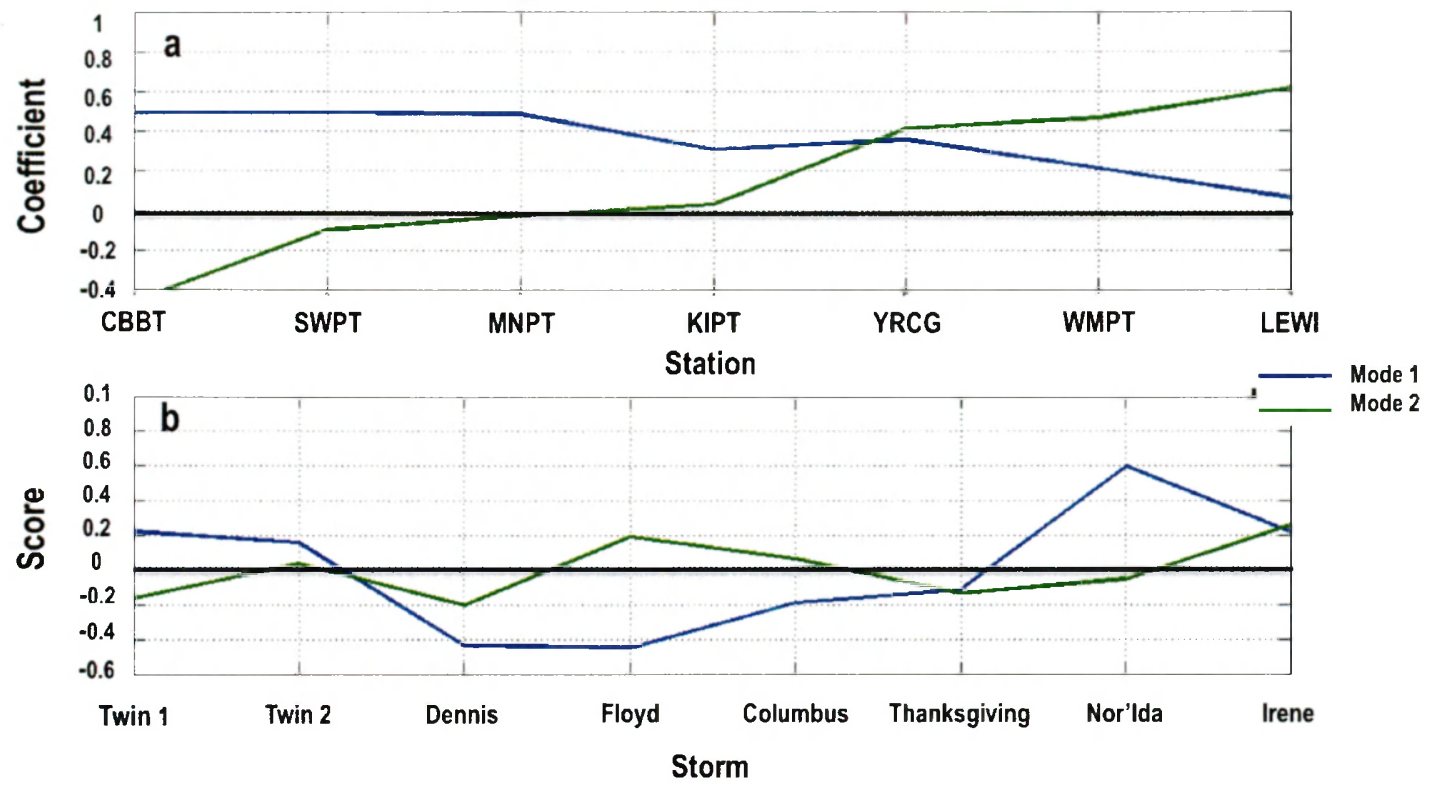

Figure 3.6: PCA outcome for maximum storm surge, excluding Washington, D.C. and Tropical Storm Ernesto. The two important PCs, are shown for each station (a). Part (b) shows the influence of each mode during these nine storms. 


\section{Tidal Range for All Stations}

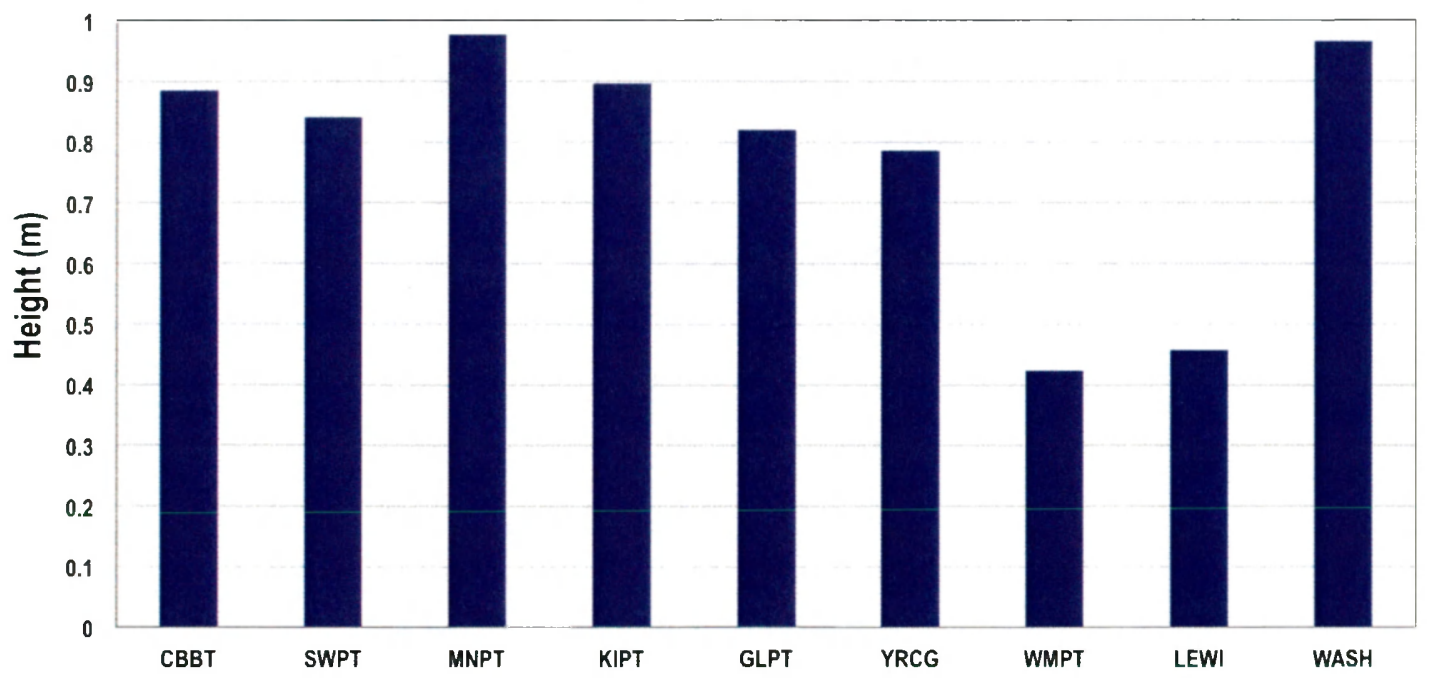

Figure 3.7: The great diurnal range, or difference in height between mean higher high and mean lower low water, for nine LCB station. 
Total Hours Above HAT per Station, 1998-2011

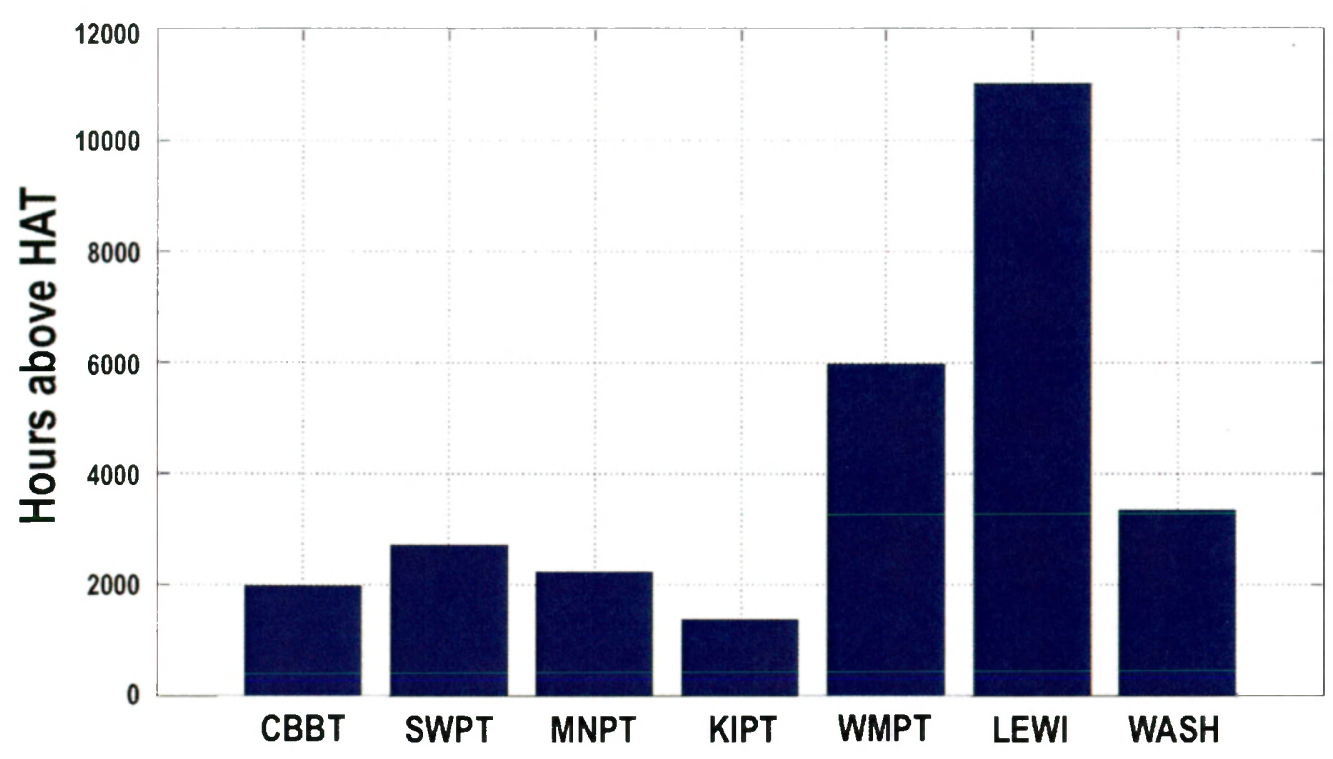

Figure 3.8: The total number of hours above HAT over the study period for each station. Gloucester Point/York River Coast Guard stations are not included. 


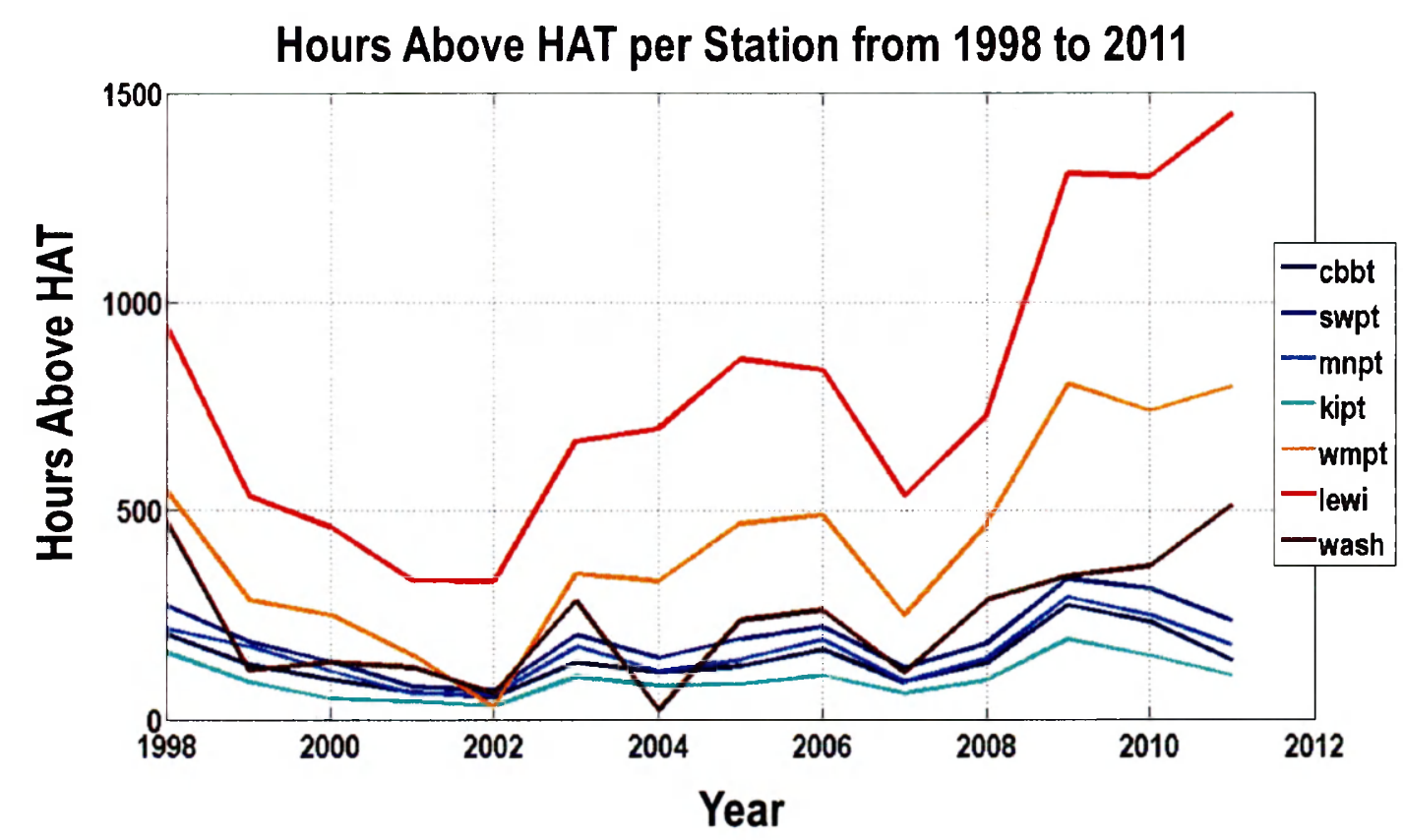

Figure 3.9: Hours above HAT per station per year over the study period. Both spatial and temporal variability is observed. 


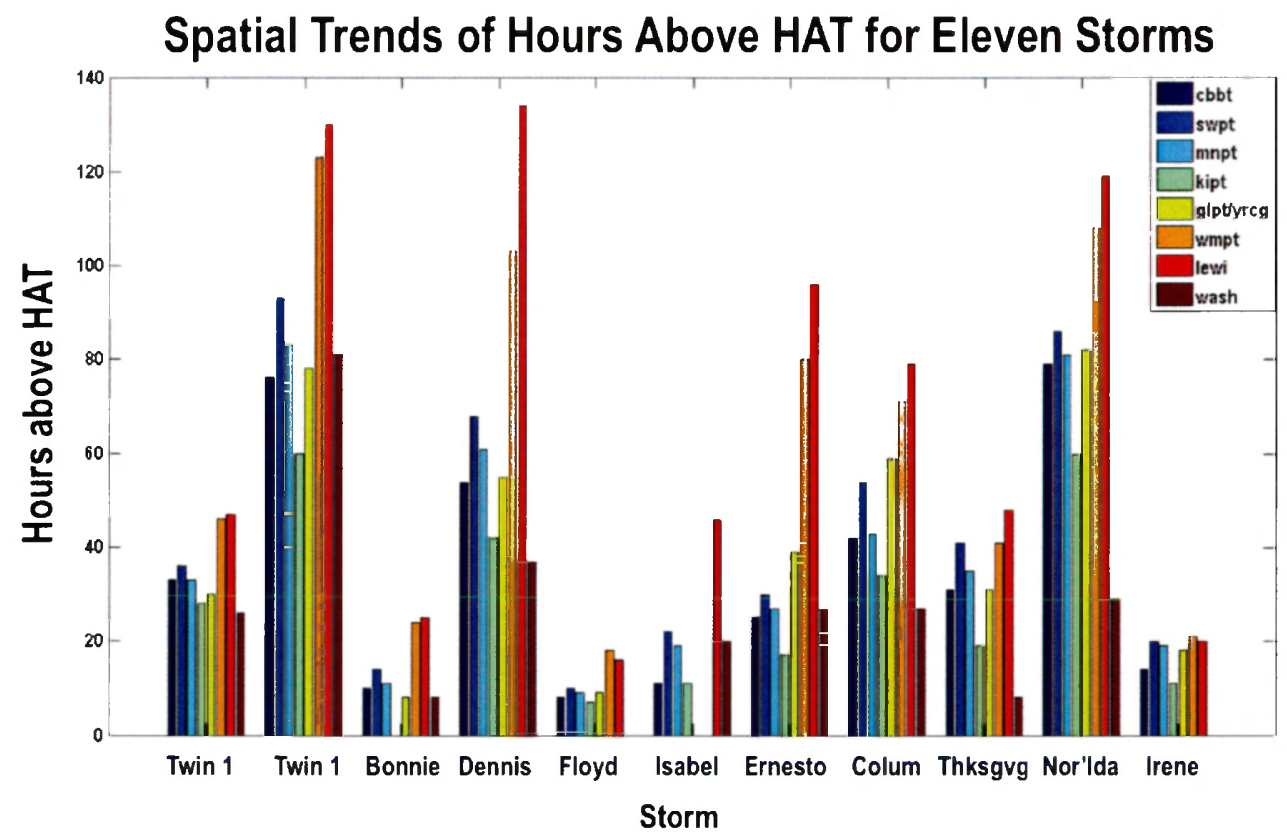

Figure 3.10: Hours above HAT shown for each station during each storm. 


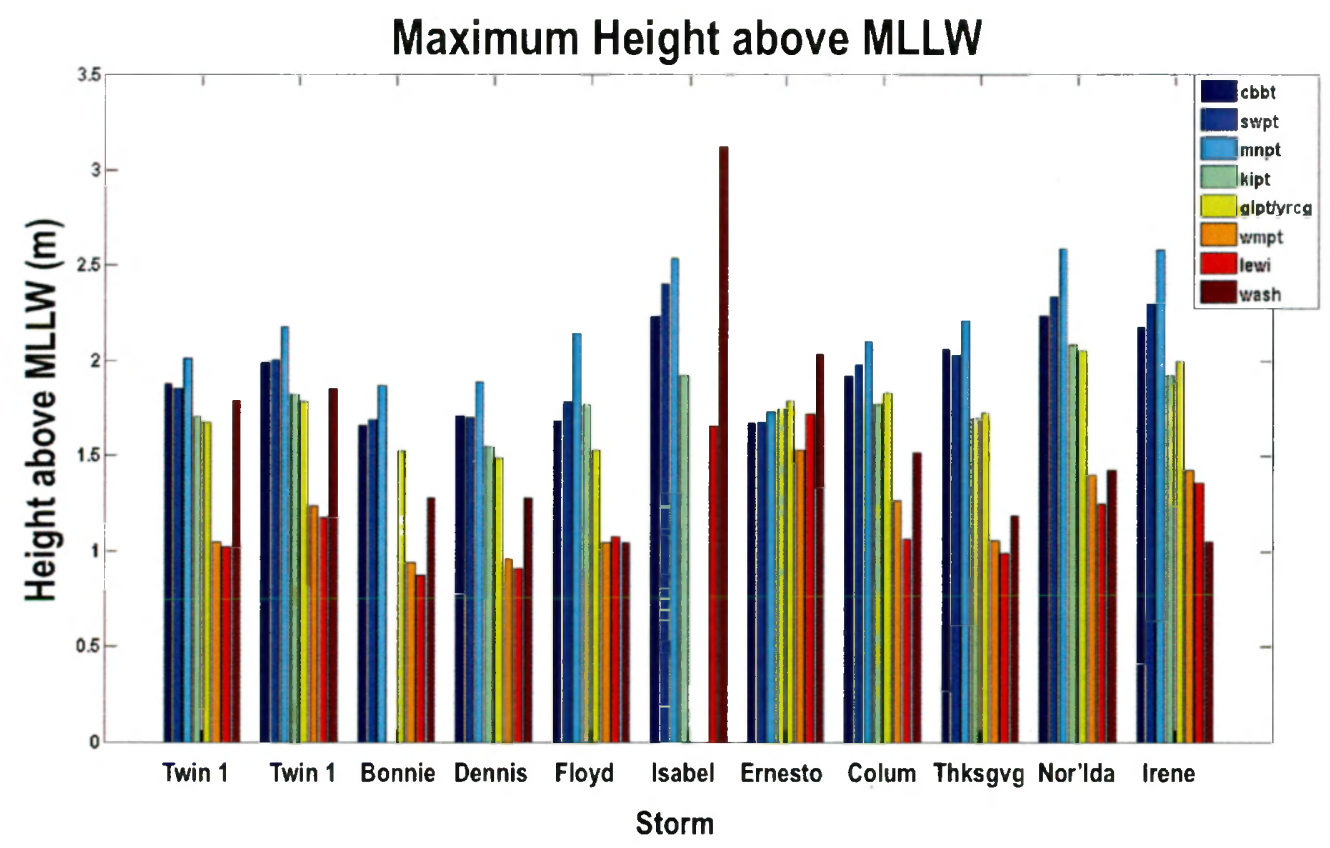

Figure 3.11: The maximum storm tide relative to MLLW for each station and storm.

South Bay stations generally exhibit larger maximum heights than Central Bay station. 


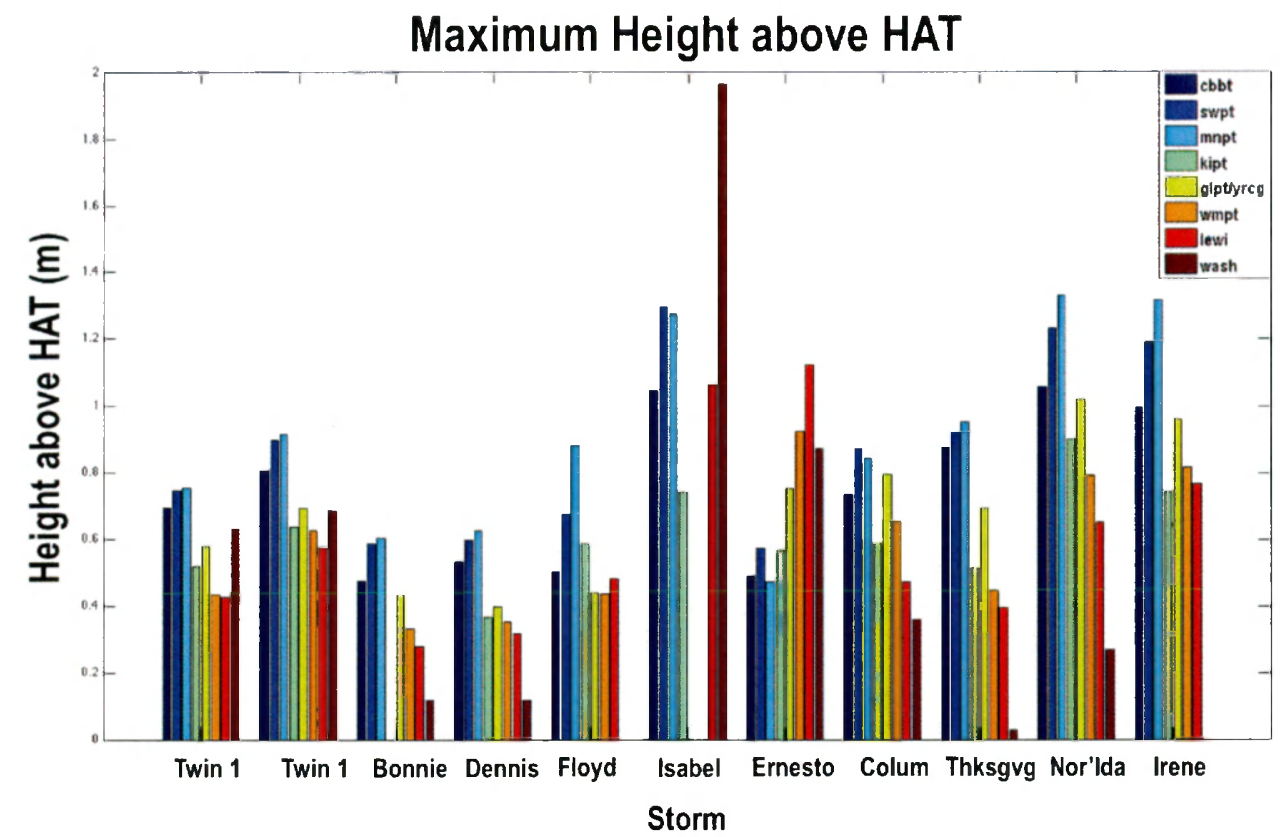

Figure 3.12: Maximum storm tide relative to HAT for each station and storm. Ernesto deviates from the rest of the storms, where the Central Bay stations have higher maximum heights above HAT than South Bay stations. 
Table 3.1: Station rankings of maximum heights relative to MLLW and HAT for Tropical Storm Ernesto.

\begin{tabular}{cccc} 
Station & Rank relative to MLLW & Rank relative to HAT & $\begin{array}{c}\text { Rank } \\
\text { Difference }\end{array}$ \\
\hline cbbt & 7 & 7 & 0 \\
swpt & 6 & 5 & 1 \\
mnpt & 4 & 8 & -4 \\
kipt & 3 & 6 & -3 \\
glpt/yrcg & 2 & 4 & -2 \\
wmpt & 8 & 2 & 6 \\
lewi & 5 & 1 & 4 \\
wash & 1 & 3 & -2
\end{tabular}


Table 3.2: Station rankings of maximum heights relative to MLLW and HAT for the Columbus Nor'easter.

\begin{tabular}{ccccc} 
& & \multicolumn{2}{c}{ Rank } \\
Station & Rank relative to MLLW & Rank relative to HAT & Difference \\
\hline cbbt & 3 & 4 & -1 \\
swpt & 1 & 2 & -1 \\
mnpt & 2 & 1 & 1 \\
kipt & 5 & 6 & -1 \\
glpt/yrcg & 4 & 3 & 1 \\
wmpt & 7 & 5 & 2 \\
lewi & 8 & 7 & 1 \\
wash & 6 & 8 & -2
\end{tabular}




\section{Spatial and Temporal View of Integrated Intensity}

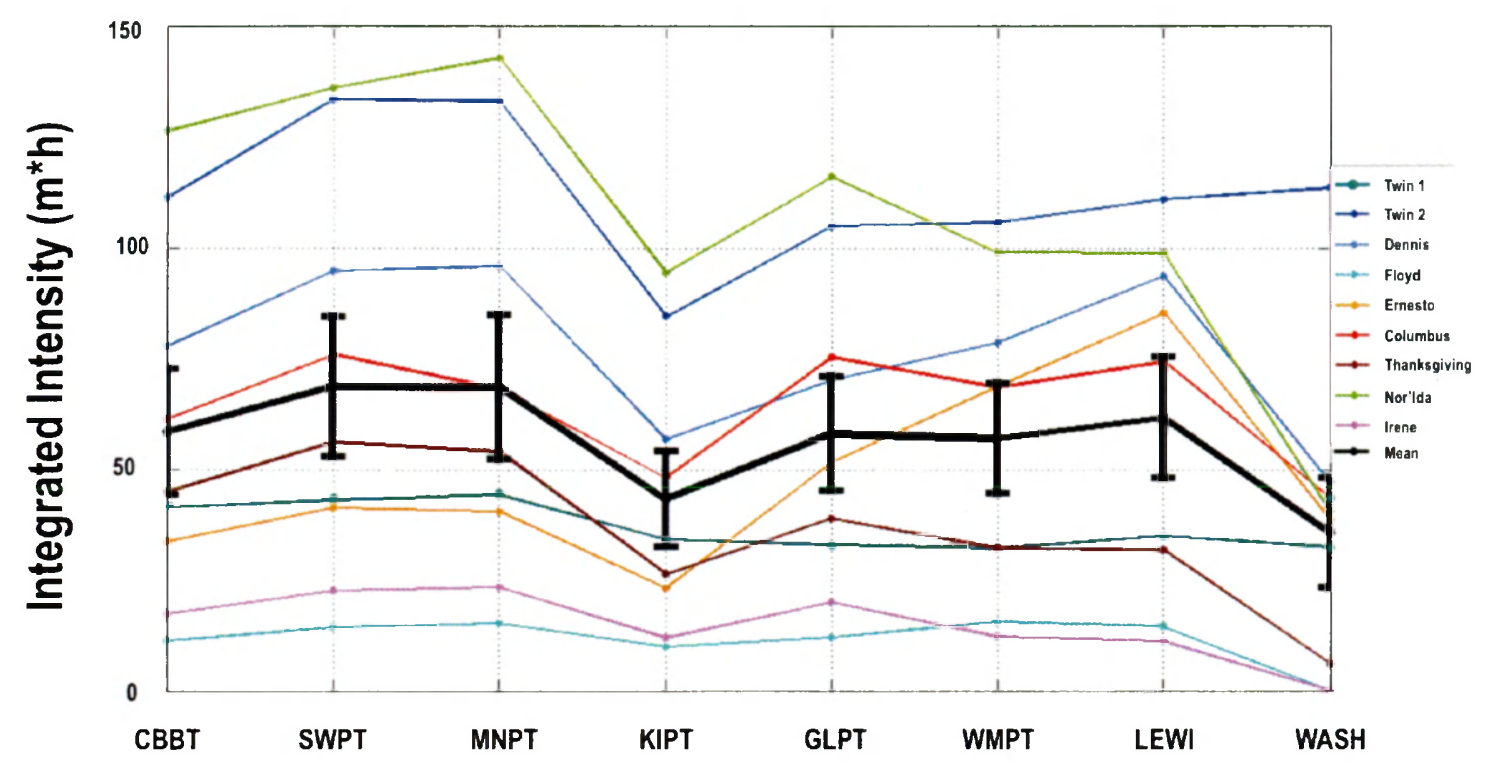

Figure 3.13: Integrated values for each storm at each station. The mean (black) of all storms for each station is plotted and error bars represent standard error. 


\section{Spatial and Storm-Series PCA Results: Integrated Intensity}

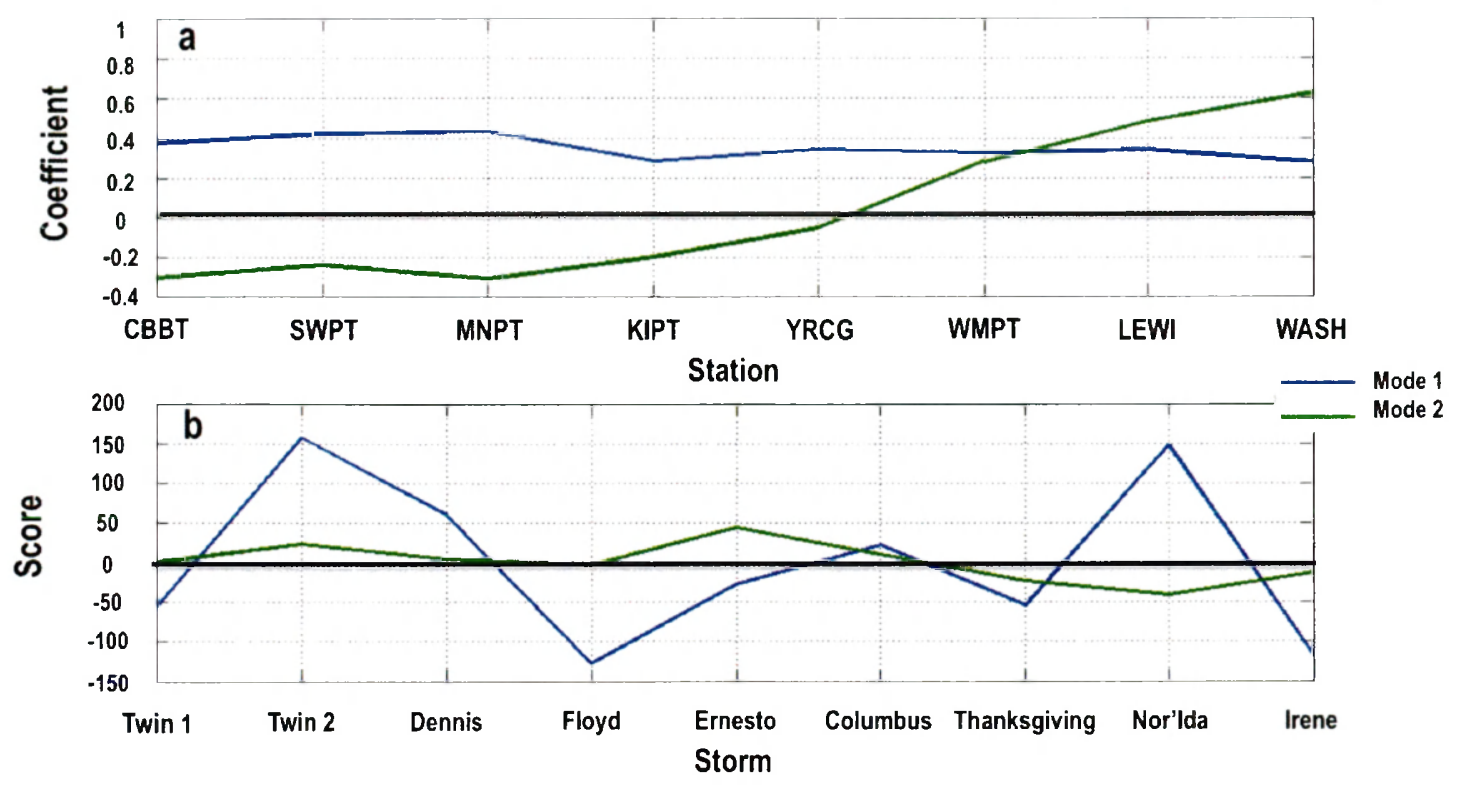

Figure 3.14: PCA outcome for the integrated intensity. The two most important PCs are shown for each station (a). Part (b) shows the influence of each mode during these nine storms. 


\section{References}

Boon, J., Brubaker, J., Forrest, D. (2010). Chesapeake Bay land subsidence and sea level change: an evaluation of past and present trends and future outlook. Special Report in Applied Marine Science and Ocean Engineering, vol. 425.

Boon, J.D. (2012). Evidence of sea level acceleration at U.S. and Canadian tide stations, Atlantic Coast, North America. Journal of Coastal Research, 28(6), 14371445.

Carter, H. H. and D. W. Pritchard (1988). Oceanography of Chesapeake Bay. In B. Kjerfve (ed.), Hydrodynamics of Estuaries, 2. Estuarine Case Studies. CRC Press, Boca Raton, Florida, pp. 1-16.

Ezer, T., \& Corlett, W.B. (2012). Is sea level rise accelerating in the Chesapeake Bay? A demonstration of a novel new approach for analyzing sea level data. Geophysical Research letters, 39, 1-6.

Knabb, R.D., \& Mainelli, M. (2006). Tropical cyclone report: Hurricane Ernesto 24 August - 1 September 2006. National Hurricane Center. http://www.nhc.noaa.gov/pdf/TCR-AL062006_Ernesto.pdf

Martinez, W. L., \& Martinez, A. (2004). Exploratory data analysis with MATLAB. CRC Press. 
APPENDIX

\section{List of Terms}

Anomaly: Water levels higher or lower than predicted for a period of one week to two months.

Highest Astronomical Tide (HAT): The elevation of the highest predicted astronomical tide expected to occur at a specific tide station over the National Tidal Datum Epoch.

Mean Lower Low Water (MLLW): The average of the lower low water height of each tidal day observed over the National Tidal Datum Epoch.

Mean Sea Level: The arithmetic mean of hourly heights observed over the National Tidal Datum Epoch.

National Tidal Datum Epoch: The specific 19-year period adopted by the National Ocean Service as the official time segment over which tide observations are taken and reduced to obtain mean values (e.g., mean lower low water, etc.) for tidal datums.

Residual: The difference between the observed water level and the NOAA predicted tide at any given point in time. 
Table A1: List of storm dates

\begin{tabular}{|c|c|c|}
\hline Storm Name & Begin Date & End Date* \\
\hline Twin Nor'easter 1 & $01 / 28 / 1998$ & $01 / 31 / 1998$ \\
\hline Twin Nor'easter 2 & $02 / 04 / 1998$ & $02 / 11 / 1998$ \\
\hline Hurricane Bonnie & $08 / 28 / 1998$ & $08 / 30 / 1998$ \\
\hline Hurricane Dennis & $08 / 30 / 1999$ & $09 / 11 / 1999$ \\
\hline Hurricane Floyd & $09 / 16 / 1999$ & $09 / 20 / 2003$ \\
\hline Hurricane Isabel & $09 / 18 / 2003$ & $09 / 05 / 2006$ \\
\hline Tropical Storm Ernesto & $08 / 30 / 2006$ & $10 / 13 / 2006$ \\
\hline Columbus Nor'easter & $10 / 05 / 2006$ & $11 / 26 / 2006$ \\
\hline Thanksgiving Nor'easter & $11 / 21 / 2006$ & $11 / 20 / 2009$ \\
\hline Nor'Ida & $11 / 11 / 2009$ & $08 / 28 / 2011$ \\
\hline Hurricane Irene & $08 / 27 / 2011$ & \\
\hline
\end{tabular}

* End date does not represent the end of the meteorological storm, but rather the date that water levels fell below HAT and remained there for at least two consecutive tidal cycles. 
Table A2: Tidal record length for all active LCB stations

\begin{tabular}{|c|c|}
\hline Station & Hourly Water Level Record \\
\hline Chesapeake Bay Bridge Tunnel & $01 / 29 / 1975$-Present \\
\hline Sewells Point & $07 / 22 / 1927-$ Present \\
\hline Money Point & $12 / 18 / 1997-$ Present \\
\hline Kiptopeke & $01 / 01 / 1996$-Present \\
\hline Gloucester Point & $01 / 01 / 1996-09 / 18 / 2003$ \\
\hline York River Coast Guard & $03 / 08 / 2004-$ Present \\
\hline Windmill Point & $01 / 01 / 1996-$ Present \\
\hline Lewisetta & $01 / 01 / 1996-$ Present \\
\hline Washington & $04 / 15 / 1931$-Present \\
\hline
\end{tabular}


Table A3: Dates of unavailable data for each station during each year throughout the study period.

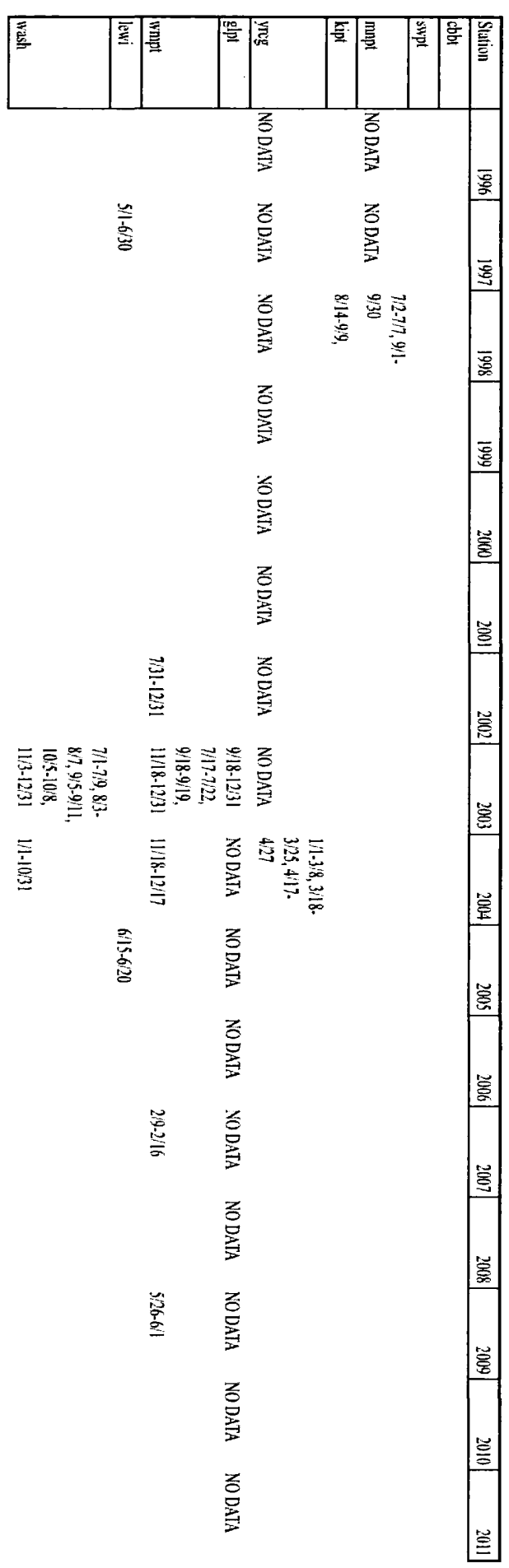


Table A4: 30 -day anomaly values

\begin{tabular}{|c|c|c|c|c|c|c|c|c|}
\hline & cbbt & swpt & mnpt & kipt & glpt & wmpt & lewi & wash \\
\hline twin1 & 0.0221 & 0.033 & 0.0126 & 0.0263 & 0.0245 & 0.0262 & 0.0459 & 0.0821 \\
\hline twin2 & 0.1726 & 0.1923 & 0.1761 & 0.1563 & 0.1676 & 0.1482 & 0.1628 & 0.2377 \\
\hline bonnie & 0.1011 & 0.1211 & 0.1133 & & 0.1111 & 0.119 & 0.1314 & 0.1189 \\
\hline dennis & 0.0853 & 0.0984 & 0.1021 & 0.088 & 0.1017 & 0.1105 & 0.1365 & 0.1066 \\
\hline floyd & 0.2323 & 0.2503 & 0.2699 & 0.2065 & 0.2345 & 0.209 & 0.223 & 0.1864 \\
\hline isabel & 0.1504 & 0.1505 & 0.1575 & 0.1186 & & & 0.1635 & \\
\hline ernesto & 0.0847 & 0.0837 & 0.0789 & 0.0687 & 0.0941 & 0.1075 & 0.1285 & 0.0744 \\
\hline columbus & 0.1727 & 0.1748 & 0.1789 & 0.1518 & 0.173 & 0.1752 & 0.1856 & 0.1402 \\
\hline tday & 0.0997 & 0.107 & 0.0968 & 0.0792 & 0.091 & 0.0837 & 0.0862 & 0.0393 \\
\hline norida & 0.3013 & 0.3018 & 0.3076 & 0.2609 & 0.3005 & 0.2708 & 0.2775 & 0.1886 \\
\hline irene & 0.1583 & 0.1673 & 0.1556 & 0.1299 & 0.1738 & 0.1954 & 0.2178 & 0.1477 \\
\hline
\end{tabular}


Table A5: Maximum anomaly-based storm surge values from each storm period at each station.

\begin{tabular}{|c|c|c|c|c|c|c|c|c|}
\hline & cbbt & swpt & mnpt & kipt & glpt/yrcg & wmpt & lewi & wash \\
\hline twin 1 & 1.2733 & 1.3097 & 1.3762 & 0.9943 & 0.9627 & 0.685 & 0.5522 & 0.8832 \\
\hline twin 2 & 1.1238 & 1.2702 & 1.3878 & 0.9322 & 1.0334 & 0.7216 & 0.6908 & 1.0451 \\
\hline bonnie & 0.8827 & 1.0516 & 1.0917 & & & 0.4993 & 0.404 & 0.5304 \\
\hline dennis & 0.9563 & 0.9916 & 1.1014 & 0.7062 & 0.7485 & 0.4803 & 0.4989 & 1.0017 \\
\hline floyd & 0.7486 & 0.9057 & 1.1283 & 0.8419 & 0.8089 & 0.6885 & 0.762 & 0.2783 \\
\hline isabel & 1.3595 & 1.6313 & 1.6746 & 1.0967 & & & 1.1354 & \\
\hline ernesto & 1.0507 & 1.2946 & 1.3493 & 0.8799 & 1.4056 & 1.1682 & 1.2615 & 1.3537 \\
\hline columbus & 0.9676 & 1.0902 & 1.1249 & 0.8265 & 1.0029 & 0.6973 & 0.6181 & 0.5615 \\
\hline thanksgiving & 1.1269 & 1.0941 & 1.2181 & 0.8262 & 0.9271 & 0.6038 & 0.5403 & 0.4126 \\
\hline norida & 1.3852 & 1.4518 & 1.6329 & 1.1079 & 1.1358 & 0.7829 & 0.6567 & 0.4965 \\
\hline irene & 1.1045 & 1.2594 & 1.3542 & 0.8916 & 1.2204 & 0.8494 & 0.8066 & 0.2583 \\
\hline
\end{tabular}


Table A6: Hours above HAT for each station and storm.

\begin{tabular}{|c|c|c|c|c|c|c|c|c|c|c|c|}
\hline & Twin 1 & Twin 2 & Bonnie & Dennis & Floyd & Isabel & Ennesto & Columbus & Thanksgivining & Nor'Ida & Trene \\
\hline chbt & 33 & 76 & 10 & 54 & 8 & 11 & 25 & 42 & 31 & 79 & 14 \\
\hline swpt & 36 & 93 & 14 & 68 & 10 & 22 & 30 & 54 & 41 & 86 & 20 \\
\hline mnpt & 33 & 83 & 11 & 61 & 9 & 19 & 27 & 43 & 35 & 81 & 19 \\
\hline kipt & 28 & 60 & & 42 & 7 & 11 & 17 & 34 & 19 & 60 & 11 \\
\hline glpt/yrcg & 30 & 78 & 8 & 55 & 9 & & 39 & 59 & 31 & 82 & 18 \\
\hline wmpt & 46 & 123 & 24 & 103 & 18 & & 80 & 71 & 41 & 108 & 21 \\
\hline lewi & 47 & 130 & 25 & 134 & 16 & 46 & 96 & 79 & 48 & 119 & 20 \\
\hline wash & 26 & 81 & 8 & 37 & & 20 & 27 & 27 & 8 & 29 & \\
\hline
\end{tabular}


Table A7: Maximum heights relative to MLLW.

\begin{tabular}{|c|c|c|c|c|c|c|c|c|c|c|c|}
\hline & Twin 1 & Twin 2 & Bonnie & Dennis & Floyd & Isabel & Emesto & Columbus & Thanksgivining & Nor'ida & Irene \\
\hline cbbt & 1.876 & 1.989 & 1.658 & 1.713 & 1.685 & 2.231 & 1.673 & 1.917 & 2.06 & 2.24 & 2.178 \\
\hline swpt & 1.85 & 2.002 & 1.692 & 1.703 & 1.781 & 2.404 & 1.68 & 1.979 & 2.028 & 2.339 & 2.297 \\
\hline mnpt & 2.014 & 2.175 & 1.868 & 1.887 & 2.145 & 2.536 & 1.733 & 2.104 & 2.215 & 2.591 & 2.58 \\
\hline kipt & 1.701 & 1.819 & 0 & 1.548 & 1.769 & 1.924 & 1.748 & 1.771 & 1.696 & 2.083 & 1.925 \\
\hline glpt/yreg & 1.671 & 1.785 & 1.526 & 1.491 & 1.533 & 0 & 1.791 & 1.832 & 1.73 & 2.056 & 1.997 \\
\hline wmpt & 1.045 & 1.238 & 0.941 & 0.963 & 1.047 & 0 & 1.535 & 1.267 & 1.058 & 1.401 & 1.426 \\
\hline Ievi & 1.023 & 1.173 & 0.875 & 0.911 & 1.079 & 1.661 & 1.721 & 1.066 & 0.99 & 1.247 & 1.362 \\
\hline wash & 1.791 & 1.849 & 1.279 & 1.278 & 1.048 & 3.125 & 2.034 & 1.522 & 1.188 & 1.429 & 1.052 \\
\hline
\end{tabular}


Table A8: Maximum heights above HAT.

\begin{tabular}{|c|c|c|c|c|c|c|c|c|c|c|c|}
\hline & Twin 1 & Twin 2 & Bonnie & Dennis & Floyd & Isabel & Emesto & Columbus & Thanksgivin & Nor'Ida & Irene \\
\hline cbbt & 0.693 & 0.806 & 0.475 & 0.53 & 0.502 & 1.048 & 0.49 & 0.734 & 0.877 & 1.057 & 0.995 \\
\hline swpt & 0.744 & 0.896 & 0.586 & 0.597 & 0.675 & 1.298 & 0.574 & 0.873 & 0.922 & 1.233 & 1.191 \\
\hline mnpt & 0.753 & 0.914 & 0.607 & 0.626 & 0.884 & 1.275 & 0.472 & 0.843 & 0.954 & 1.33 & 1.319 \\
\hline kipt & 0.519 & 0.637 & 0 & 0.366 & 0.587 & 0.742 & 0.566 & 0.589 & 0.514 & 0.901 & 0.743 \\
\hline glpt/yrcg & 0.578 & 0.692 & 0.433 & 0.398 & 0.44 & 0 & 0.753 & 0.794 & 0.692 & 1.018 & 0.959 \\
\hline wmpt & 0.434 & 0.627 & 0.33 & 0.352 & 0.436 & 0 & 0.924 & 0.656 & 0.447 & 0.79 & 0.815 \\
\hline lewi & 0.428 & 0.578 & 0.28 & 0.316 & 0.484 & 1.066 & 1.126 & 0.471 & 0.395 & 0.652 & 0.767 \\
\hline wash & 0.629 & 0.687 & 0.117 & 0.116 & 0 & 1.963 & 0.872 & 0.36 & 0.026 & 0.267 & 0 \\
\hline
\end{tabular}


Table A9: Integrated Intensity Values.

\begin{tabular}{|c|c|c|c|c|c|c|c|c|}
\hline & cbbt & swpt & mnpt & kipt & glpt & wmpt & lewi & wash \\
\hline \begin{tabular}{|l|} 
Twin 1 \\
\end{tabular} & 41.27 & 42.966 & 44.29 & 34.182 & 32.915 & 32.221 & 34.954 & 32.383 \\
\hline Twin 1 & 111.332 & 133.324 & 132.908 & 84.576 & 104.906 & 105.76 & 110.932 & 113.537 \\
\hline Dennis & 77.66 & 94.662 & 95.853 & 56.84 & 70.185 & 78.648 & 93.593 & 47.055 \\
\hline Floyd & 11.223 & 14.324 & 15.223 & 9.93 & 12.083 & 15.563 & 14.566 & 0 \\
\hline Ernesto & 33.528 & 41.227 & 40.478 & 23.048 & 51.512 & 68.598 & 85.287 & 38.543 \\
\hline Columbus & 61.177 & 75.832 & 68.197 & 48.013 & 75.347 & 68.496 & 74.336 & 43.271 \\
\hline Thanksgiving & 44.802 & 56.072 & 54.016 & 26.396 & 38.84 & 32.194 & 31.72 & 5.97 \\
\hline Norida & 126.363 & 136.036 & 142.736 & 94.444 & 116.074 & 99.008 & 98.726 & 40.281 \\
\hline Irene & 17.289 & 22.589 & 23.367 & 11.909 & 19.997 & 12.209 & 11.166 & 0 \\
\hline
\end{tabular}



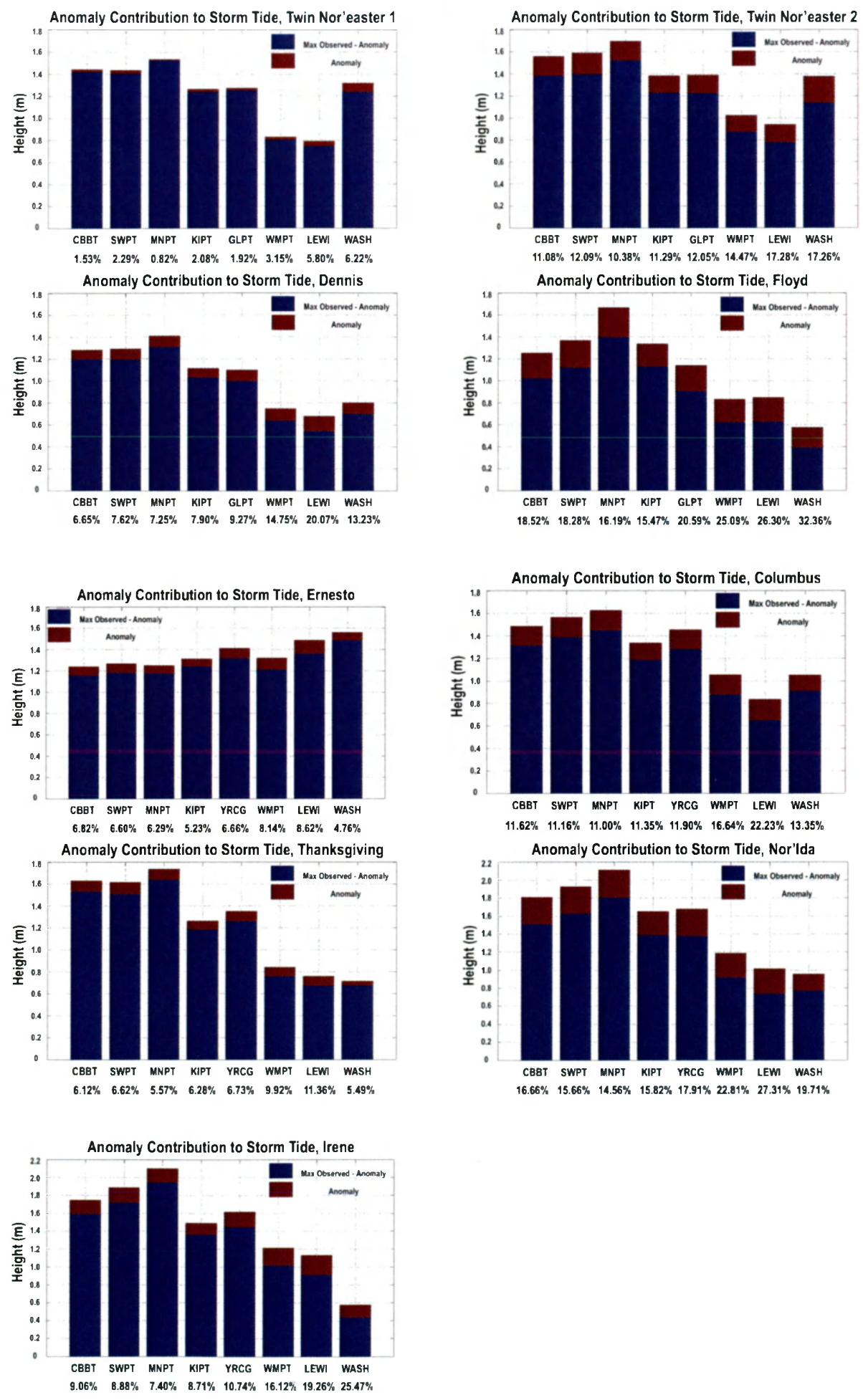

Figure A1: Anomaly contribution to storm tide in both value and percentage for all stations and storms, except Hurricanes Bonnie and Isabel. 

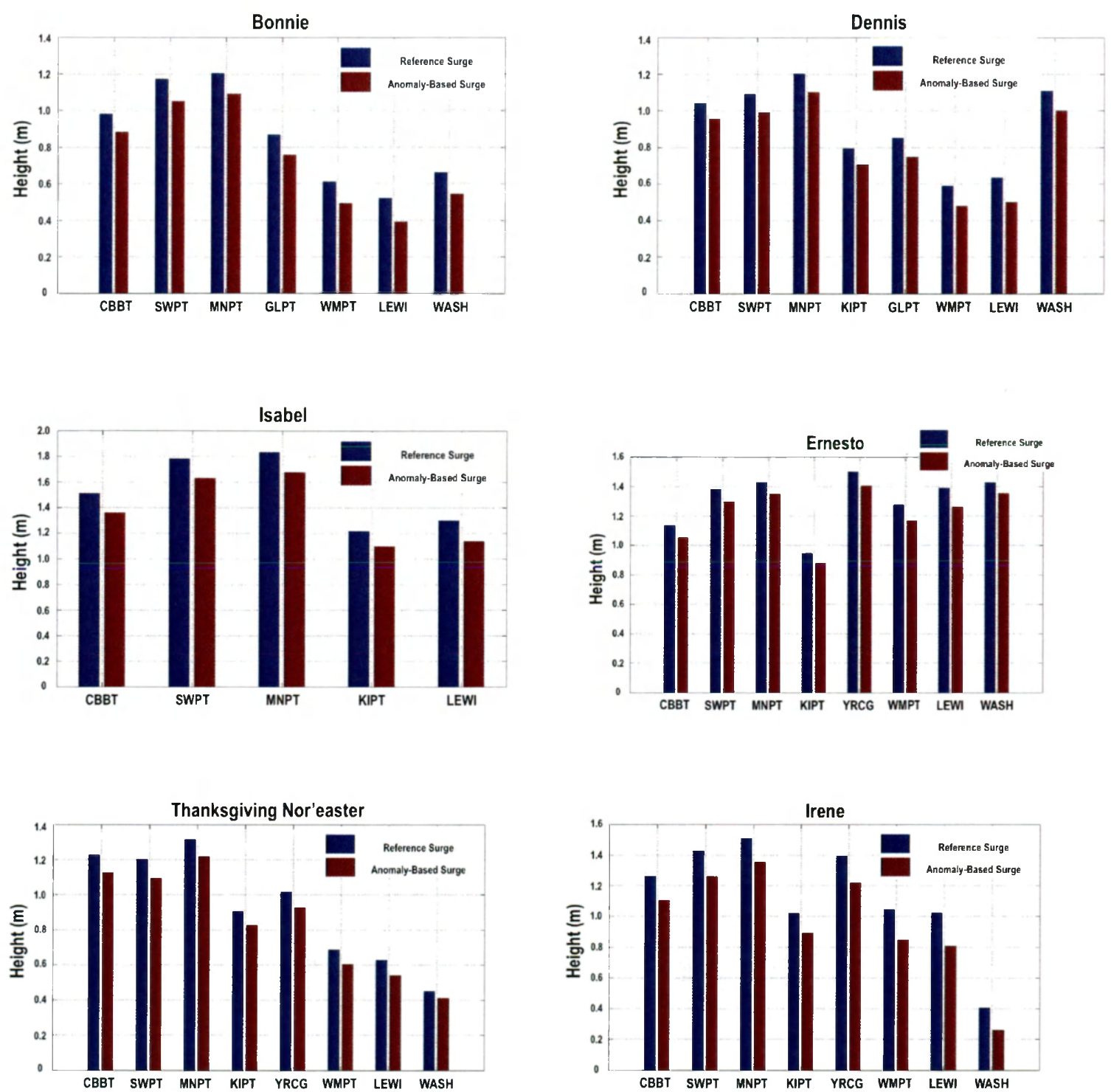

Figure A2: In addition to figure 2.4 (a-e), reference surges and anomaly-based surges for all remaining storms are shown here. 

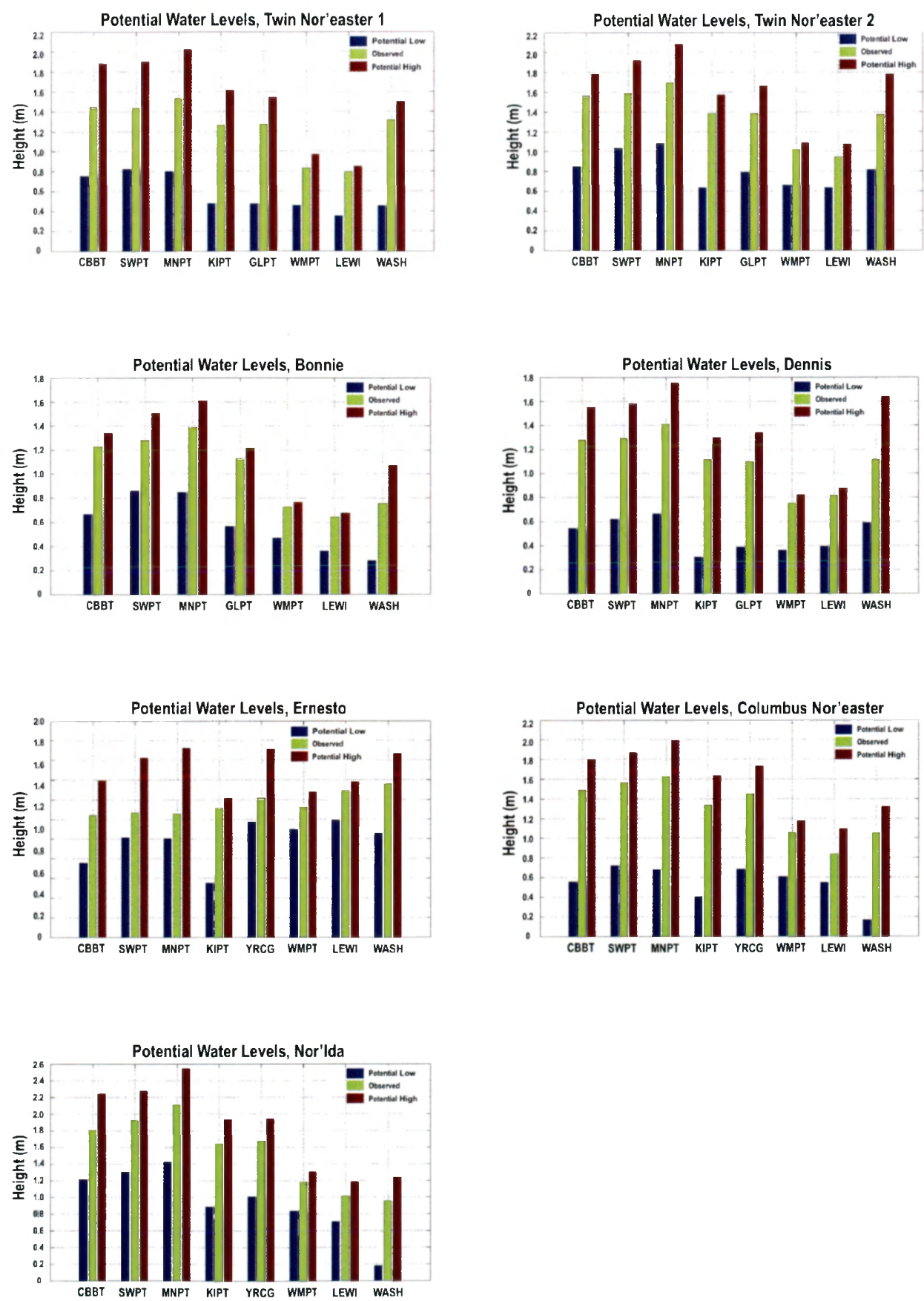

Figure A3: In addition to figure 2.5 (a-d), potential low and high water levels as well as the maximum observed level for all remaining storms are shown here. 


\section{Vita}

\section{Carissa Nichelle Wilkerson}

Born July 13, 1988 in West Chester, Pennsylvania. Graduated from B. Reed Henderson High School in 2006. Earned a B.S. in Marine and Environmental Science in 2010. Entered M.S. program at the College of William and Mary, School of Marine Science in 2010 . 